\title{
Application of the Direct Displacement Based Design Methodology for Different Types of RC Structural Systems
}

\author{
Saleh Malekpour ${ }^{1)}$, and Farhad Dashti ${ }^{2), *}$
}

(Received August 6, 2012, Accepted April 4, 2013)

\begin{abstract}
This study investigates the direct displacement based design (DDBD) approach for different types of reinforced concrete structural systems including single moment-resisting, dual wall-frame and dual steel-braced systems. In this methodology, the displacement profile is calculated and the equivalent single degree of freedom system is then modeled considering the damping characteristics of each member. Having calculated the effective period and secant stiffness of the structure, the base shear is obtained, based on which the design process can be carried out. For each system three frames are designed using DDBD approach. The frames are then analyzed using nonlinear time-history analysis with 7 earthquake accelerograms and the damage index is investigated through lateral drift profile of the models. Results of the analyses and comparison of the nonlinear time-history analysis results indicate efficiency of the DDBD approach for different reinforced concrete structural systems.
\end{abstract}

Keywords: direct displacement based design, RC frame systems, time-history analysis, accelerograms.

\section{Introduction}

In recent years, there has been a great tendency toward performance-based seismic design of structures. In this connection, various methods have been developed among which Capacity Spectrum Method (Freeman 1998), the N-2 Method (Fajfar 2000), and Direct Displacement-Based Design can be enumerated. A relatively new performance-based seismic design procedure called the direct displacement-based design (DDBD) proposed by Priestley and Kowalsky (2000) has recently received notable acceptance among researchers. It seems that the methods could be a rational alternative to traditional erroneous force-based seismic design of structures. The method defines the design performance level of the structure in terms of displacement limits. Therefore, displacement is the key parameter of the design method.

This paper investigates the DDBD of different types of reinforced concrete structural systems including single moment-resisting, dual wall-frame and dual steel-braced systems. There is a need for a design methodology that is applicable to dual system structures, because the dynamic

\footnotetext{
${ }^{1)}$ Department of Structural Engineering, School of Civil Engineering, University of Tabriz, 51664 Tabriz, Iran. ${ }^{2)}$ Department of Civil and Natural Resources

Engineering, University of Canterbury, Christchurch 8140, New Zealand.

*Corresponding Author; E-mail: farhad.dashti@pg.canterbury.ac.nz Copyright $($ The Author(s) 2013. This article is published with open access at Springerlink.com
}

behaviour of dual systems is considerably different from pure frame or wall or steel braced structures for which many design recommendations already exist. Such differences in dynamic behaviour are attributed principally to the interaction that takes place between different structural systems, which is not well accounted for in current design practice.

A further motivation for this study comes from the fact that combination of different structural systems results in an efficient earthquake-resisting system, and considering structural and aesthetic points of view combination of the structural systems presents considerable advantage over structures formed purely out of frames or walls or bracing systems.

The displacement based design of RC structures has been addressed increasingly in recent years, and the displacement based design of multiple degree of freedom RC structures has been the main philosophy of these approaches. Gulkan and Sozen (1974) investigated the nonlinear behavior of RC structures under dynamic loads, and presented equivalent equations for damping of single degree of freedom structures. Shibata and Sozen (1976) presented the substitute structure methodology for RC structures, and intended to devise a displacement based design method. Moehle (1992) suggested the general outline of a seismic resistant design approach based on the inter-story relative displacement calculation using displacement response spectrum. Although the initial step of design using this approach is also calculation of stiffness, elastic time period and different strengths of the structure, it is quite different from the traditional methods as includes direct control of displacements instead of indirect control using ductility coefficients. The initial step of the approach recommended by Kowalsky et al. (1995) for single degree of freedom structures is determination of the maximum target displacement which can be obtained based on the ductility 
capacity being proportional to details of the members. Assuming an acceptable value for yield displacement, the designer converts the maximum displacement to the demand displacement ductility, and using a series of displacement response spectrums with different damping values (due to ductility values), calculates the effective period of the single degree of freedom structure in the maximum displacement. The ultimate results of the calculated yield strength based on the maximum displacement and secant stiffness is corresponding to the effective period. Calvi and Kingsley (1995), and Calvi and Pavese (1995) generalized this approach for the structures with multiple degrees of freedom. It should be noted that the ultimate results of all these approaches are the demand strength values based on which sections and dimensions of the members shall be computed.

In recent years, new approaches have been proposed which use different methodologies. Fardis et al. (1997) presented an approach based on the ultimate state design for gravity loads and displacement control under the service level characteristics. Chopra and Goel (2001) presented the application procedure of the inelastic design spectrum in DDBD. Assuming an initial displacement profile, Priestley and Kowalsky (2000) suggested a general design procedure for RC structures, following which Sullivan et al. (2006) developed the DDBD method for RC frame-wall structures. Sullivan et al. (2005) investigated a trial methodology which provided encouraging results when applied to regular frame-wall structures in which the frames were parallel to the walls. The research identified that the following two tasks were required to improve the accuracy of the methodology and thereby enable the Direct DBD (Priestley 2003) approach to be used for frame-wall structures:

- Development of an expression for the displaced shape of frame-wall structures at maximum response, to enable equivalent SDOF characteristics to be established.

- Development of an expression for the equivalent SDOF system ductility or equivalent viscous damping that takes into account the frame-wall interaction.

Sullivan et al. (2005) proposed that the design displacement profile be set as a function of the moment profile in the walls, using proportions of strength assigned at the start of the design procedure. There is experimental evidence that supports the validity of this approach as reported by Sullivan et al. (2004). Another recommendation made by Sullivan et al. (2005) was that the equivalent SDOF system viscous damping could be obtained by factoring the individual frame and wall components by the proportions of overturning they resist. The challenge in this paper is therefore to finalize the design procedure proposed by Sullivan et al. (2005) and to verify its accuracy through examination of a range of case study structures.

Belleri (2009) suggested the performance based design approach for RC precast buildings in 2009. Sullivan et al. (2009) investigated a DDBD code in 2009. Garcia et al. (2010) investigated the DDBD approach for steel frame-RC wall dual systems in 2009. Pennucci et al. (2009) studied the DBD for RC precast wall-damper systems.

$\mathrm{RC}$ buildings with steel bracings are the new structural systems addressed in rehabilitation of RC structures in recent years and researches are extensively investigating on application of steel bracing systems in such buildings. The research conducted by Higashi et al. (1981) on application of $\mathrm{CBF}$ and EBF bracing systems in rehabilitation of $\mathrm{RC}$ frames and the studies of Badox and Jirsa (1990) on nonlinear behavior modeling of bracing systems in RC frames can be cited as examples. Maheri and Sabahi (1997) suggested the direct connection of the internal bracing to the RC frame. Tasnimi and Masoomi (1999) experimentally investigated the direct use of steel bracings in RC frames. For this purpose, the manufactured frames were subjected to static gravity loads and cyclic lateral loads. The results indicated that adding bracing to an RC frame, depending on the utilized details, considerably increases the equivalent stiffness of the frame and leads to notable change in its behavior. Ghaffarzadeh and Maheri (2006a, b) showed that different directly connected internal bracing systems can be used effectively in retrofitting of the existing concrete frames as well as shear resisting elements for the construction of new RC structures. Having conducted two cyclic experiments on an RC moment-resisting frame and an RC frame with steel bracings, Youssef et al. (2007) came to the conclusion that the braced frame has more ductility and can resist greater lateral load. Maheri and Ghaffarzadeh (2008) investigated the amount of the interaction force between the RC frame and the steel bracing analytically and experimentally using the experiments conducted on RC moment resisting frames and RC frames with steel bracings. Malekpour et al. (2012) developed steps of the Displacement Based Design method for RC frames with steel bracings.

In this study, considering the ever increasing development of the DDBD and its use in RC buildings, the DDBD methodology is investigated for three lateral load resisting systems of reinforced concrete structures, i.e., RC Frame, RC Wall-Frame and Steel-Braced RC Frame Systems. For this purpose, the displacement profile is calculated and the equivalent single degree of freedom system is then modeled considering the damping characteristics of each member. Having calculated the effective period and secant stiffness of the structure, the base shear is obtained, based on which the design process can be carried out. For each system three frames are designed using DDBD approach. The frames are then analyzed using nonlinear time-history analysis with 7 earthquake accelerograms and the damage index is investigated through lateral drift profile of the models. Results of the analyses and comparison of the nonlinear time-history analysis results indicate efficiency of the DDBD approach for different reinforced concrete structural systems located in near-field regions.

\section{Description of the Design Procedure}

This section briefly describes the design procedure used in this study. Figure 1 displays the whole procedure using 4 successive steps. In DDBD methodology, the original structure is substituted with an equivalent SDOF system (Fig. 1a). This equivalent system is represented by a secant 
stiffness $\left(K_{e}\right)$ at maximum response (Fig. 1b), equivalent viscous damping including both the viscous and hysteretic dampings inherent in the real structure, and an effective mass $\left(m_{e}\right)$ and height (Fig. 1a). Also, a set of equations define the mathematical relationship between displacement ductility and damping and a set of design displacement spectra have been used throughout the design process.

Assuming a design ductility, which is choosed by the designer based on ultimate design displacement and yield displacement of the real structure as $\mu_{\Delta}=\Delta_{\mathrm{D}} / \Delta_{\mathrm{y}}$, or simply based on code requirements, and using existing ductilitydamping diagrams, a design damping is selected for the equivalent SDOF system (Fig. 1c). Then, a design period is obtained using Fig. 1d and according to the specified design displacement and the specified equivalent viscous damping.

\subsection{Assignment of Strength Proportions for Dual Systems}

In order to develop the equivalent SDOF structure, strength proportions are assigned, by which the shear and moment profiles in the braces and shear walls can be established. The story shear above the base of the walls and bracings cannot be obtained directly from the design base shear. As such, wall shears and bracing shears are obtained as the difference between the total shear and the frame shear as shown in Eqs. (1a) and (1b). Recall that the frame story shear can be determined since it is dependent only on the strength of the beams up the building height (Sullivan et al. 2006).

$$
\begin{aligned}
& \frac{V_{i, \text { brace }}}{V_{b}}=\frac{V_{i, \text { total }}}{V_{b}}-\frac{V_{i, \text { frame }}}{V_{b}} \\
& \frac{V_{i, \text { wall }}}{V_{b}}=\frac{V_{i, \text { total }}}{V_{b}}-\frac{V_{i, \text { frame }}}{V_{b}}
\end{aligned}
$$

where, $V_{b}$ is the total base shear, $V_{i, \text { brace }}$ is the bracing shear at level $i, V_{i, \text { wall }}$ is the wall shear at level $i$ and $V_{i, \text { total }}$ is the total shear at level $i$, and $V_{i \text {,frame }}$ is the frame shear at level $i$.

For the purpose of establishing the inflection height, a triangular distribution of the fundamental mode inertia forces along the height of the structure is assumed. This approximation enables the total storey shear to be obtained as a function of the base shear as shown in Eq. (2) (Sullivan et al. 2006).

$$
\frac{V_{i, t o t a l}}{V_{b}}=1-\frac{i(i-1)}{n(n+1)}
$$

where $V_{i, t o t a l}$ is the total shear at level $i, V_{b}$ is the total base shear, and $\mathrm{n}$ is the total number of stories in the building. Assuming that beam moments are carried equally by

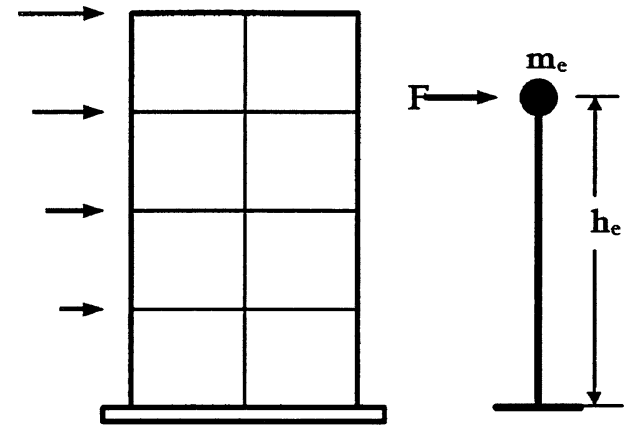

(a) SDOF Simulation

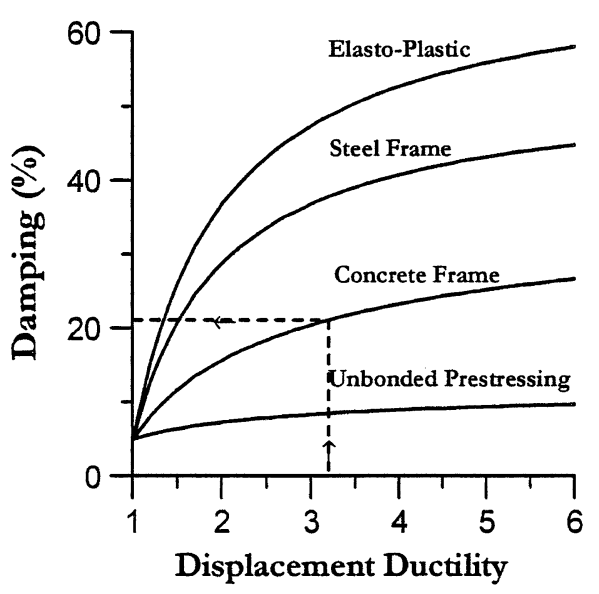

(c) Equivalent damping vs. ductility

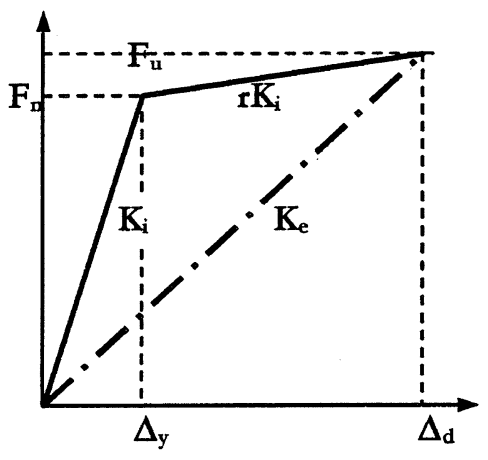

(b) Effective Stiffness $K_{e}$

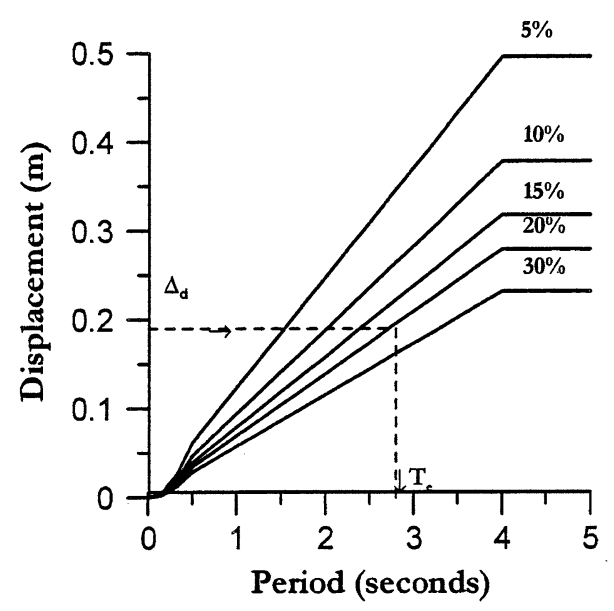

(d) Design Displacement Spectra

Fig. 1 Direct displacement-based design concept: a Equivalent SDOF system, b effective secant stiffness, c equivalent damping versus ductility, d design displacement spectra (Pettinga and Priestley 2005). 
columns above and below a beam-column joint, the frame storey shear is obtained as a function of the beam strength using Eq. (3) (Sullivan et al. 2006).

$$
V_{i, f r a m e}=\frac{\left(\sum M_{b, i}+\sum M_{b, i-1}\right)}{2\left(h_{i}-h_{i-1}\right)}=\frac{\sum M_{b, i}}{h_{c o l}}
$$

where, $V_{i, f r a m e}$ is the frame shear at level $i, M_{b, i}$ is the beam moment at level $i$, and $h_{c o l}$ is the inter-storey height. Although the beam strengths are not actually known to begin with, Eq. (3) is useful as it indicates that provided beams of equal strength are to be used, thus the frame storey shear is constant along the building height. Consequently, if $40 \%$ of the base shear is being carried by the frames, this $40 \% V_{b}$ will be carried along the entire height of the frame. As such, the shear proportion carried by the frame can be substituted in Eqs. (1a) and (1b) and the brace shears and bending can be calculated, all as a function of the design base shear (Ghorbani-Asl 2007).

\subsection{Yield Deformation and Design Displacement Profile of Frames, Bracings and Walls}

The ductility demands of the frames at level $\mathrm{i}$ can be obtained using Eq. (4).

$$
\mu_{\text {frame }, i}=\left(\frac{\Delta_{i}-\Delta_{i-1}}{h_{i}-h_{i-1}}\right) \frac{1}{\theta_{\text {yframe }}}
$$

where, $\mu_{\text {frame }, i}$ is the frame ductility at level $i$, and $\theta_{y \text { frame }}$ is the yield drift of the frame (from Eq. (5) (Priestley 2003)).

$$
\theta_{y \text { frame }}=\frac{0.5 l_{b} \varepsilon_{y}}{h_{b}}
$$

where $\Delta_{i}, \Delta_{i-1}, h_{i}$, and $h_{i-1}$, are the displacements and heights at level $i$ and level $i-1$, respectively.

The design displacement profile is developed using the various values obtained as the following for each of the systems, together with the design story drift using Eqs. (6) to $(13)$.

For RC frame models:

$$
\begin{array}{ll}
n \leq 4: & \Delta_{i}=\theta_{d} \cdot h_{i} \\
n \geq 4: & \Delta_{i}=\theta_{d} \cdot h_{i}\left(1-0.25 \frac{h_{i}}{h_{n}}\right)
\end{array}
$$

In Eq. (6), $\theta d$ is design story drift, $h_{i}$ is the i-th story height, and $\mathrm{n}$ is the number of stories. It has been suggested by Pettinga and Priestley (2005) that the $\Delta_{i}$ be multiplied by a reduction factor of 0.85 . In this study, this factor was found to be effective and therefore was included in calculating story design displacement. The design inter-story drift $\left(\theta_{d}\right)$ was considered to be $2.5 \%$ for this study

$$
\Delta_{y}=0.5 \varepsilon_{y}\left(\frac{l_{b}}{h_{b}}\right)\left(0.6 h_{m}\right)
$$

In Eq. (7), $\varepsilon_{y}, l_{b}, h_{b}$ and $h_{m}$ are yield strain of longitudinal bars, bay length, beam height and effective height of the structures (which can be assumed to be $0.7 h_{n}$ for framed structures), respectively.

For RC wall-frame models:

$$
\Delta_{i}=\Delta_{i y}+\left(\theta_{d}-\frac{\phi_{y} \text { wall } h_{\mathrm{inf}}}{2}\right) \cdot h_{i}
$$

The displacement profile of the structure at yield of the wall, $\Delta_{i y}$, can then be established using the wall yield curvature, inflection height and storey height in accordance with Eq. (9a, 9b).

$$
\begin{aligned}
& \Delta_{i y}=\frac{\phi_{y \text { Wall }} \cdot h_{\mathrm{inf}} h_{i}}{2}-\frac{\phi_{y \text { Wall }}\left(h_{\mathrm{inf}}\right)^{2}}{6} \text { for } h_{i} \geq h_{\mathrm{inf}} \\
& \Delta_{\text {iy }}=\frac{\phi_{y \text { Wall }} h_{i}^{2}}{2}-\frac{\phi_{y \text { Wall }} h_{i}^{3}}{6 h_{\mathrm{inf}}} \text { for } h_{i}<h_{\mathrm{inf}}
\end{aligned}
$$

The yield curvature of the walls, $\phi_{y \text { Wall }}$, is firstly obtained using Eq. (10) (Priestley 2003).

$$
\phi_{y} \text { wall }=\frac{2 \varepsilon_{y}}{L_{w}}
$$

where $\varepsilon_{y}$ is the yield strain of the longitudinal reinforcement in the wall and $L_{w}$ is the wall length.

$\theta_{d}$ is the design storey drift, and $h_{i}$ is the height at level $i$. Note that the design story drift can be initially taken as the code limit for non-structural damage, reduced to allow for higher mode effects in accordance with Eq. (11).

$$
\theta_{d}=\theta_{d, \lim i t}\left[1-\frac{(N-5)}{100}\left(\frac{M_{O T, \text { frame }}}{M_{O T, \text { total }}}+0.25\right)\right] \leq \theta_{d, \lim i t}
$$

where $N$ is the number of stories, MOT, frame is the overturning resistance of the frame and MOT, total is the total overturning resistance of the structure. This approximate equation was proposed after reviewing the results of initial trial case studies (Sullivan et al. 2006). As mentioned before, the ratio of frame to total overturning resistance can be obtained in terms of the base shear using the strength assignments made at the start of the design procedure.

For Steel braced RC frame models:

$$
\Delta_{i}=\Delta_{i y}+\left(\theta_{d}\right) \cdot h_{i}
$$

The yield deformation of bracing is calculated using Eq. (13) (Ghorbani-Asl 2007).

$$
\Delta y_{i}=\frac{F_{y} L_{b r i}}{E \cos \theta_{i}}
$$

where $F_{y}$ is the yield stress of steel, $L_{b r i}$ is length of the bracing element at Level $i, E$ is the steel modulus of elasticity, and $\theta$ refers to the orientation of the bracing elements in the undeformed configuration. 


\subsection{Equivalent SDOF Characteristics}

With knowledge of the displacement profile at maximum response; $\Delta_{i}$, the seismic masses; $m_{i}$, and storey heights; $h_{i}$, the equivalent SDOF design displacement; $\Delta_{d}$, effective mass; $m_{e}$, and effective height; $h_{e}$, can be calculated as shown in Eqs. (14-16) (Sullivan et al. 2004), respectively.

$$
\begin{aligned}
& \Delta_{d}=\frac{\sum_{i=1}^{n}\left(m_{i} \Delta_{i}^{2}\right)}{\sum_{i=1}^{n}\left(m_{i} \Delta_{i}\right)} \\
& m_{e}=\frac{\sum_{i=1}^{n}\left(m_{i} \Delta_{i}\right)}{\Delta_{d}} \\
& h_{e}=\frac{\sum_{i=1}^{n}\left(m_{i} \Delta_{i} h_{i}\right)}{\sum_{i=1}^{n}\left(m_{i} \Delta_{i}\right)}
\end{aligned}
$$

\subsection{Determine the Design Base Shear and Member Strengths}

With the effective period established, the effective stiffness, $K_{e}$, is determined in accordance with Eq. (17).

$$
k_{e}=4 \pi^{2} \frac{m_{e}}{T_{e}^{2}}
$$

where $m_{e}$ is the effective mass (from Eq. (15)) and $T_{e}$ is the effective period. This effective stiffness is then multiplied by the design displacement, $\Delta_{d}$, to obtain the base shear, $V_{b}$, as shown by Eq. (18).

$$
V_{b}=K_{e} \Delta_{d}
$$

Individual member strengths are then determined maintaining the strength proportions assigned at the start of the design process. Note however that rather than using a triangular lateral force distribution, better results are obtained distributing the base shear along the height of the structure according to Eq. (19).

$$
F_{i}=\frac{m_{i} \Delta_{i}}{\sum_{i=1}^{N} m_{i} \Delta_{i}} V_{b}
$$

where, $F_{i}$ is the portion of base shear applied at level $i, m_{i}$ is the mass at level $i$, and $\Delta_{i}$ the displacement at level $i$.

\subsection{Equivalent Viscous Damping}

One of the most important parameters required for DDBD approach is equivalent viscous damping. Thus, in this section the methodology used for calculation of this parameter is given for the structural systems investigated in this study.

Equivalent viscous damping is a function of ductility and the effective period (Malekpour et al. 2012; Priestley and Grant 2005; Blandon 2004).

When beams of equal strength are used along the height of the structure, the ductility obtained from Eq. (4) for each story can be averaged to give the frame displacement ductility demand. The proposed procedure determines the equivalent damping in such a way that when this damping is applied to a SDOF system with a definite effective period which is obtained based on the secant stiffness in the maximum displacement response, response of this SDOF system becomes consistent with the nonlinear time-history analysis response. Finally, the objective is to propose an equation that calculates the equivalent damping factor for DDBD. In order to obtain the equivalent damping, the following method which is based on Blandon's method (Blandon 2004) is used.

The process is repeated for effective periods from 0.5 to $4 \mathrm{~s}$ each $0.5 \mathrm{~s}$, for 5 ductility levels from 2 to 6 . Six different hysteretic curves are used and all the cases are analyzed for six records.

Step 1: Initially, an effective period $\left(T_{\text {eff }}\right)$ and a ductility level $(\mu)$ are selected.

$$
T_{e, t r i a l}=\frac{N}{6} \sqrt{\mu_{s y s}}
$$

where $N$ is the total number of stories and $\mu_{\text {sys }}$ is the system ductility.

Step 2: The equivalent damping factor $\xi$ is estimated. For the first iteration this was based on Jacobsen's approach (Jacobsen 1930) according to the hysteretic loop considered. However, after the results of the first iteration were obtained, the equivalent damping was changed in the next iterations to improve the substitute structure/time-history agreement. The significant assumption of this step would be definition of the initial viscous damping factor $\xi_{0}$ which is assumed equal to zero to prevent its effect.

Step 3: The average damped displacement spectrum is determined, as shown in Fig. 2.

Step 4: An initial response displacement $\left(\Delta_{\text {spec }}\right)$ is obtained from the actual average damped spectrum (non-smoothed) for the selected effective period $T_{\text {eff }}$, as shown in Fig. 2.

Step 5: For a given hysteretic model, the initial stiffness $\left(K_{i n i}\right)$ and yielding force $\left(F_{y}\right)$ are defined using $\Delta_{\text {spec }}$, mass $\left(m_{\text {eff }}\right)$, effective period $\left(T_{e f f}\right)$ and the ductility $(\mu)$ as follows:

$$
\begin{aligned}
& \Delta y=\frac{\Delta s p e c}{\mu} \\
& k_{\text {eff }}=\frac{4 \pi^{2} m_{\text {eff }}}{T_{\text {eff }}^{2}}, F_{\max }=k_{\text {eff }} \cdot \Delta_{\text {spec }}
\end{aligned}
$$

The yield force $F_{y}$ can be found from the ductility and maximum response force using hysteretic-model-specific equations. The initial stiffness $K_{i n i}$ can then be computed as:

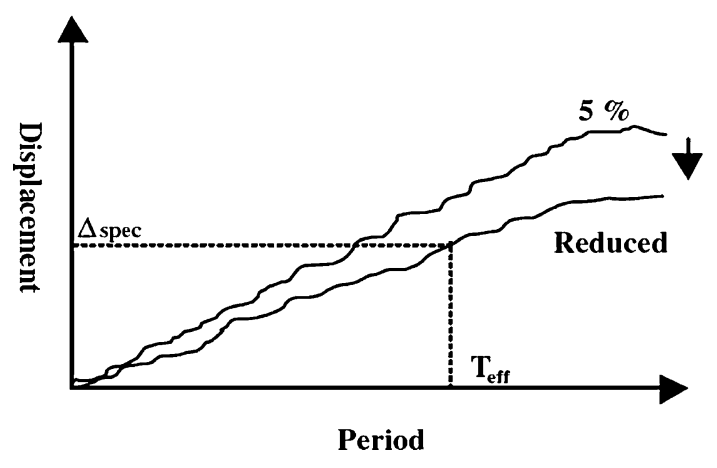

Fig. 2 Average damped displacement spectrum. 


$$
K_{\text {ini }}=\frac{F y}{\Delta y}
$$

Step 6: Time-history analysis is run for each of the records and the maximum displacements are obtained.

Step 7: The displacements obtained from Step 6 are compared with that from Step 4.

Step 8: If the displacements are similar (within a tolerance of $3 \%$ ), the damping factor is not changed and the process is repeated from Step 1 with the next $T_{\text {eff }}$ and $\mu$; otherwise, the damping factor is modified and the process is repeated from Step 2.

Using Eq. (24), the equivalent damping parameters can be calculated (Priestley and Grant 2005).

$$
\begin{aligned}
\xi_{\text {hyst.frame }}= & \frac{120}{1.3 \pi}\left(1-\frac{1}{\mu_{\text {frame }}^{0.5}}-0.1 r \mu_{\text {frame }}\right) \\
& \times\left(1+\frac{1}{\left(T_{\text {e.trial }}+0.85\right)^{4}}\right)
\end{aligned}
$$

where $r$ is the post-elastic stiffness coefficient, typically taken as 0.05 for new RC structures. Damping for the equivalent SDOF system is determined using Eq. (25) (Priestley and Grant 2005).

$$
\xi_{\text {SDOF }}=\xi_{\text {hyst,frame }}
$$

For RC wall fram, wall equivalent viscous damping components are calculated using Eq. (26)

$$
\begin{aligned}
& \xi_{\text {hyst }, \text { wall }}=\frac{95}{1.3 \pi}\left(1-\frac{1}{\mu_{\text {wall }}^{0.5}}-0.1 r \mu_{\text {wall }}\right) \\
& \left(1+\frac{1}{\left(T_{e, \text { trial }}+0.85\right)^{4}}\right)
\end{aligned}
$$

The equivalent viscous damping for equivalent SDOF system is determined using Eq. (27) (Priestley and Grant 2005).

$$
\xi_{\text {SDOF }}=\frac{M_{\text {wall }} \cdot \xi_{\text {wall }}+M_{O T, \text { frame }} \cdot \xi_{\text {frame }}}{M_{\text {wall }}+M_{O T, f r a m e}}
$$

where, $M_{O T \text {,frame }}$ is the overturning resistance of the frames and $M_{\text {brace }}$ is the overturning resistance (flexural strength) of the braces.

Note: $\zeta_{\text {frame }}$ is calculated using Eq. (24)

For Steel braced RC frame models, the constitutive model considered for the steel bracing to calculate the equivalent viscous damping is Ramberg-Osgood model, and the loading curve complies with Eq. (28) (Blandon 2004).

$$
\frac{D}{D_{y}}=\frac{F}{F_{y}}\left(1+\left(\frac{F_{0}}{F_{y}}\right)^{y-1}\right)
$$

Finally, Blandon proposed the EVDF for six different constitutive models using statistical approaches and the equations are presented in Eq. (29).

$$
\begin{aligned}
& \xi_{\text {brace }}=\frac{a}{\pi}\left(1-\frac{1}{\mu^{b}}\right) \cdot\left(1+\frac{1}{(T+c)^{d}}\right) \cdot \frac{1}{N} \\
& N=1+\frac{1}{(0.5+c)^{d}}
\end{aligned}
$$

where $a, b, c$ are the constant coefficients defined for each hysteresis model and are given in Table $1, \mu$ is the ductility factor, $\mathrm{T}$ is the effective period, and $\mathrm{N}$ is the normalization factor and the model considered in this study is RambergOsgood model.

The equivalent viscous damping for equivalent SDOF system is determined using Eq. (30) (Malekpour et al. 2012).

$$
\xi_{\text {SDOF }}=\frac{M_{\text {brace }} \zeta_{\text {brace }}+M_{O T, \text { frame }} \cdot \xi_{\text {frame }}}{M_{\text {brace }}+M_{O T, \text { frame }}}
$$

Note: $\zeta_{\text {frame }}$ is calculated using Eq. (24).

At this point of the design process, the equivalent viscous damping has been established for the systems being investigated and as such, the displacement spectrum is developed at the design level of damping. This can be done using a damping-dependent scaling factor appropriate for the seismological characteristics of the design region. CEN (1998) recommends that the $\eta$ value obtained from Eq. (31) be used to scale the elastic spectrum to the damping level of interest.

$$
\eta=\sqrt{10 /\left(5+\xi_{S D O F}\right)} \geq 0.55
$$

where, $\xi_{S D O F}$ is the equivalent viscous damping of the system as given by Eqs. (25), (27), and (30). The design displacement is then used to read (or interpolate between known points) the required effective period, $T_{e}$, as shown in Fig. 2.

The spectral values of all the other damping values, excluding damping $5 \%$, with modification factor of EC8 CEN (1998) is obtained as Eq. (32).

$$
\Delta(T, \xi)=\Delta(T, 5)\left(\frac{10}{5+\xi}\right)^{\frac{1}{2}}
$$

where, $\xi$ is the structure damping and is expressed as a percentage of the critical damping for the considered design limits.

The effective period obtained from Fig. 2 is compared with the initial period. If this period does not agree with the

Table 1 Constants of Ramberg-Osgood hysteresis model.

\begin{tabular}{c|c}
\hline Constant & Value \\
\hline \hline$a$ & 150 \\
\hline$b$ & 0.45 \\
\hline$c$ & 1 \\
\hline$d$ & 4 \\
\hline
\end{tabular}


initial period, replaces the initial period and the process is repeated. When the effective period agrees with the initial period, it will be the design period and will be used for obtaining the design base shear.

\subsection{Design Flowcharts}

In this section the DDBD methodology employed for the above mentioned systems is clarified via the flowcharts shown in Figs. 3, 4, and 5. For each system three 4-, 8- and 12-story models are designed based on the corresponding chart.

\subsubsection{RC Frame Systems}

The DDBD parameters calculated for the RC frame models are given in Table 2.

\subsubsection{RC Wall-Frame Systems}

The DDBD parameters calculated for the RC wall-frame models are given in Table 3 .

\subsubsection{RC Steel Braced Frame Systems}

The DDBD parameters calculated for the steel braced RC frame models are given in Table 4.

\section{Structural Models}

Three 4-story, 8-story and 12-story buildings with three different structural configurations (RC Frame, RC WallFrame and Steel Braced RC Frame Systems) are designed based on the DDBD approaches mentioned in each section and according to the following considerations.

The structures are assumed to be residential, placed in a very high seismicity region with Soil Type II and according to the Iranian Code of Practise for Seismic Design of Buildings (Standard No. 2800, third edition (2005)). The material properties are as the following:

$$
\begin{gathered}
f_{c}^{\prime}=30 \mathrm{MPa} ; \quad E_{C}=25740 \mathrm{MPa} ; \quad f_{y}=400 \mathrm{MPa} ; \\
E_{s}=200000 \mathrm{MPa}
\end{gathered}
$$

An internal 2D frame is selected from each of the 4-story, 8 -story and 12-story buildings. The frames are $3.5 \mathrm{~m}$ in height and have 3 spans with $5 \mathrm{~m}$ in width. Figures 6,7 and 8 display the schematic views of the above mentioned systems.

The cross section profiles that are designed for the members using DDBD approach are given in Tables 5, 6 and 7 .

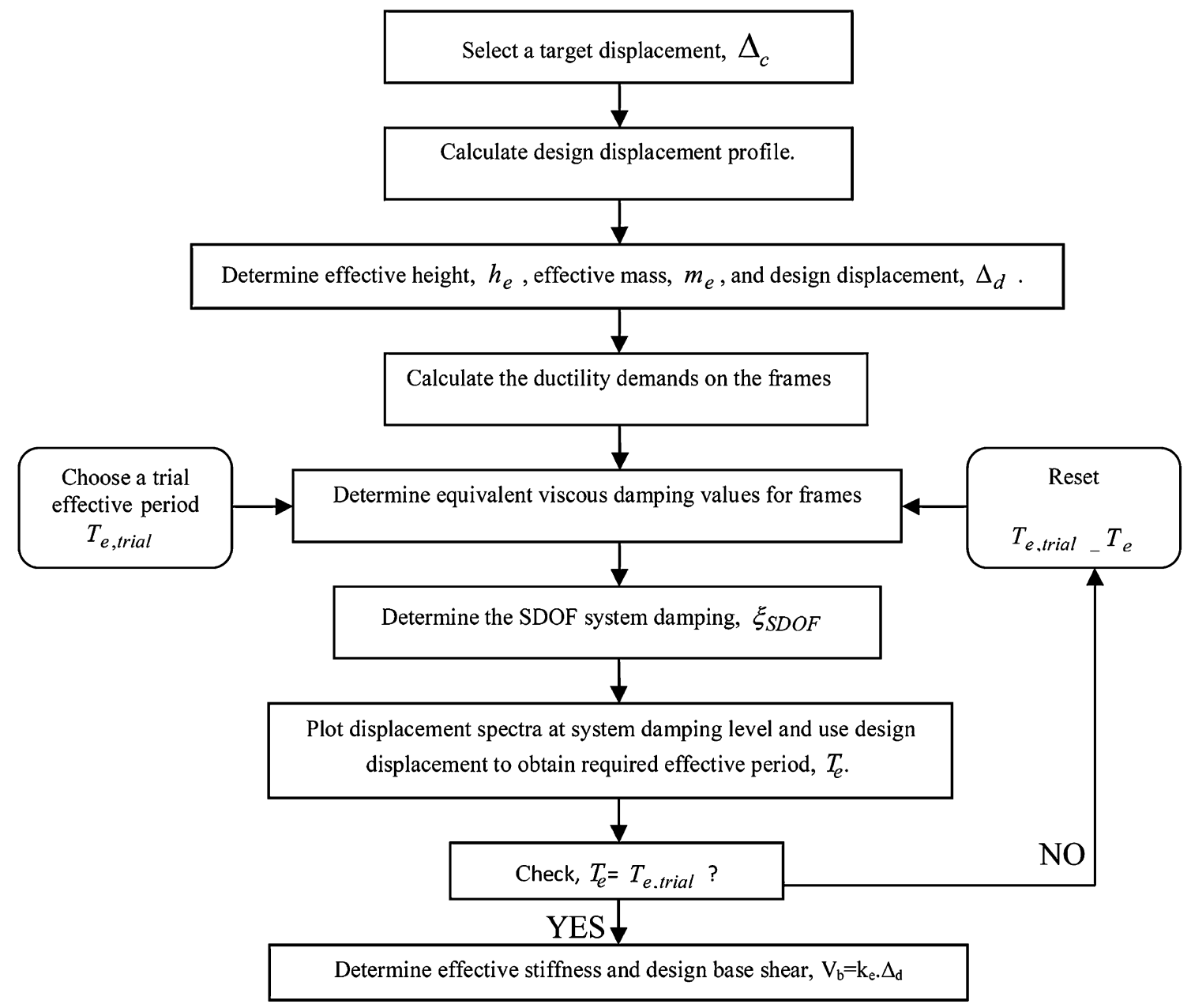

Fig. 3 DDBD flowchart for RC frames. 


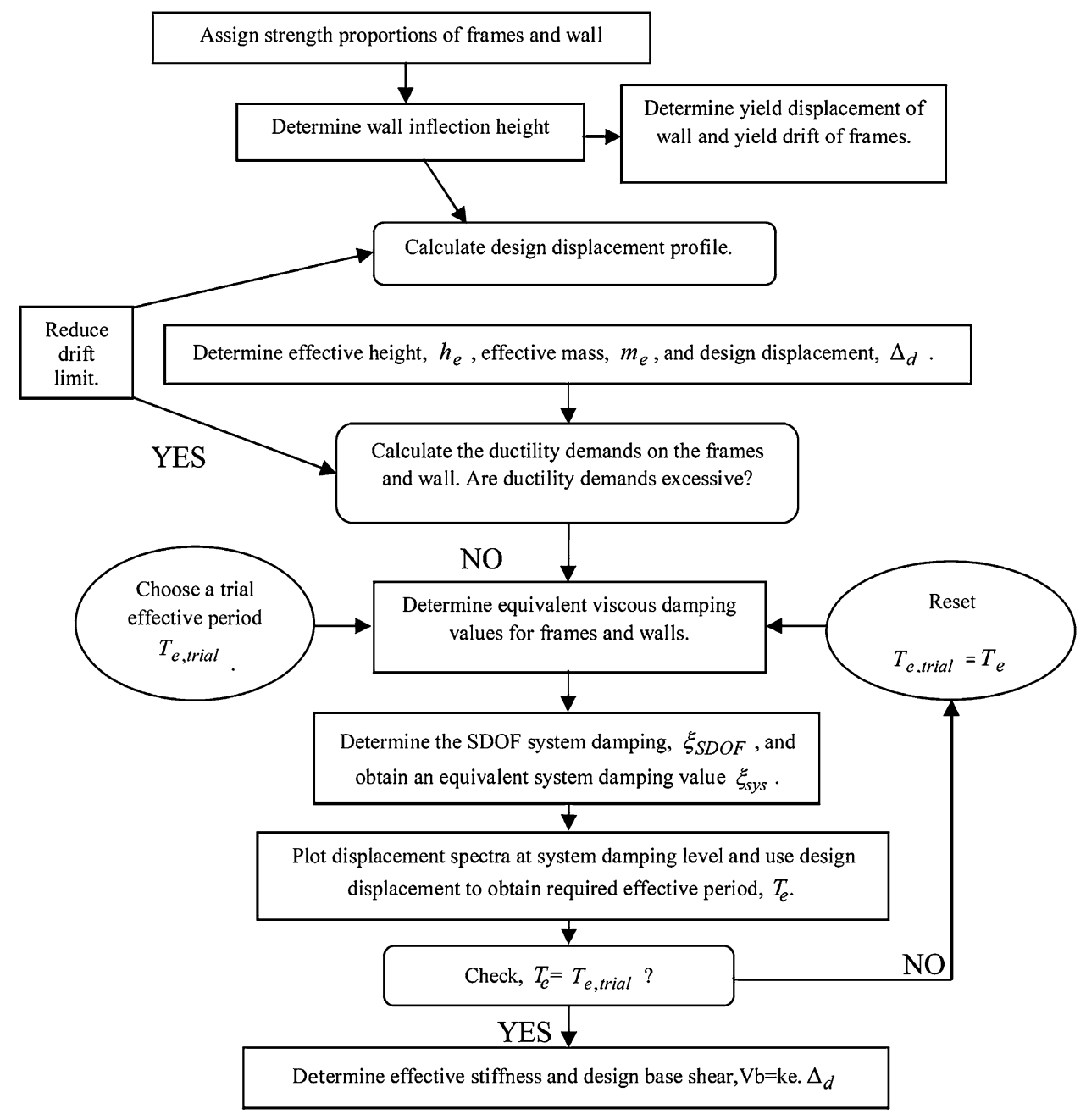

Fig. 4 DDBD flowchart for RC wall-frames.

\section{Performance Verification}

In order to evaluate seismic performance of the structures designed using this method, the nonlinear time-history analysis is carried out using PERFORM 3D (2006). For this purpose, FEMA concrete beam and FEMA concrete column have been used to model inelastic bending in concrete beams and columns, based on the FEMA 356 model. Brace Element is used for bracings and fiber elements are used for simulation of shear walls. Each FEMA beam component is actually two components, namely a plastic hinge and an elastic segment (Fig. 9).

The model for a FEMA concrete beam is similar to that for a steel beam. However, rotation hinges are used, instead of curvature hinges. This is because FEMA-356 gives the properties for concrete beams and columns in terms of plastic end rotations rather than as multiples of the yield rotation.

Most of the inelastic components in PERFORM-3D have the same form for the F-D relationship. This is a trilinear relationship with optional strength loss, as shown in Fig. 10. For further description about the key points of the F-D relationship please refer to reference FEMA (2002). The widely used hysteretic models of Ramberg-Osgood (from
Blandon 2004) and Takeda (from Blandon 2004) were implemented for simulating the reinforcing steel and concrete behavior, respectively (Figs. 11, 12).

Rayleigh damping is used in PERFORM-3D (2006) for time-history analysis of the structures.

Rayleigh damping assumes that the structure has a damping matrix, $C$, given by:

$$
C=\alpha M+\beta K
$$

where $M$ is the structure mass matrix, $K$ is the initial elastic stiffness matrix, and $\alpha$ and $\beta$ are multiplying factors.

The physical meaning of $\alpha \mathrm{M}+\beta \mathrm{K}$ damping is illustrated in Fig. 13 (PERFORM-3D 2006).

The models simulated using this software have been subjected to 7 accelerograms which were scaled to the utilized design spectrum. Table 8 shows some of the most important specifications of the records, and the elastic acceleration response spectrum of these accelerograms is indicated in Fig. 14.

Assignment of the base shear to the frames, walls and bracing elements of the analytical models are shown in Figs. 15 and 16. 


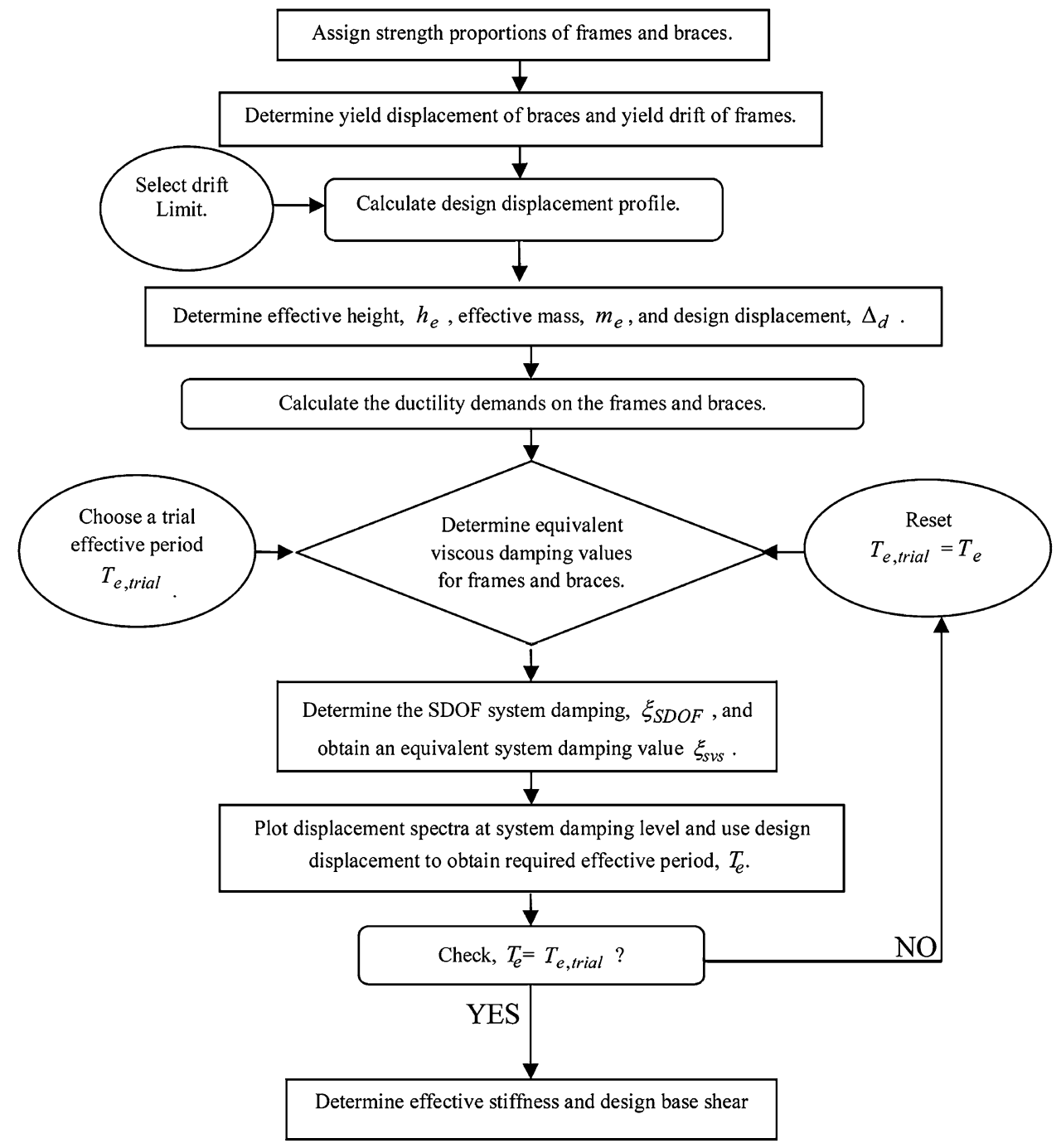

Fig. 5 DDBD flowchart for steel braced RC frames.

Table 2 DDBD parameters calculated for RC frame models.

\begin{tabular}{c|c|c|c}
\hline & 4 storey & 8 storey & 12 storey \\
\hline \hline Drift limit $\theta_{d}$ & 0.025 & 0.025 & 0.025 \\
\hline Effective mass $m_{e}(\mathrm{~kg})$ & 192,660 & 375,680 & 567,920 \\
\hline Effective height $H_{e}(\mathrm{~mm})$ & 9,105 & 17,650 & 26,320 \\
\hline Design displacement $\Delta_{d}(\mathrm{~mm})$ & 240 & 404 & 525 \\
\hline Equivalent damping $\xi_{e q}$ & 12.58 & 12.64 & 12.2 \\
\hline Effective period $T(\mathrm{~s})$ & 1.4 & 2.1 & 3 \\
\hline Base shear $(\mathrm{kN})$ & 914 & 1,282 & 1,332 \\
\hline
\end{tabular}

Calculating the design displacement profile is one of the most important steps of DDBD. Figures 17, 18 and 19 display the displacement profiles of the 4,8 and 12 story models for RC frame models, RC wall-frame and steel braced RC frame models, respectively.

In this section, a very important verification parameter, namely "inter-story drift" is discussed. Many studies have shown that inter-story drift has a key role in damage potential of structures. Generally, building codes limit inter-story drift to values within the range of $2-2.5 \%$ of the story height. As mentioned earlier, a value of $2.5 \%$ was selected for this study. The inter-story drift response of the models are displayed in Figs. 20, 21 and 22 . 
Table 3 DDBD parameters calculated for RC wall-frame models.

\begin{tabular}{c|c|c|c}
\hline & 4 storey & 8 storey & 12 storey \\
\hline \hline Drift limit $\theta_{d}$ & 0.025 & 0.025 & 0.025 \\
\hline Effectivemass $m_{e}(\mathrm{~kg})$ & 795,167 & $1,575,298$ & $2,298,357$ \\
\hline Effective height $H_{e}(\mathrm{~mm})$ & 10,876 & 20,602 & 30,450 \\
\hline Design displacement $\Delta_{d}(\mathrm{~mm})$ & 256 & 475 & 663 \\
\hline Equivalent damping $\xi_{e q}$ & 12 & 11.25 & 10.14 \\
\hline Effective period $T(\mathrm{~s})$ & 1.79 & 2.76 & 3.50 \\
\hline Base shear $(\mathrm{kN})$ & 2,504 & 3,875 & 4,907 \\
\hline
\end{tabular}

Table 4 DDBD parameters calculated for steel braced RC frame models.

\begin{tabular}{c|c|c|c}
\hline & 4 storey & 8 storey & 12 storey \\
\hline \hline Drift limit $\theta_{d}$ & 0.025 & 0.025 & 0.025 \\
\hline Effective mass $m_{e}(\mathrm{~kg})$ & 229,836 & 462,550 & 694,873 \\
\hline Effective height $H_{e}(\mathrm{~mm})$ & 9,670 & 18,390 & 27,140 \\
\hline Design displacement $\Delta_{d}(\mathrm{~mm})$ & 230 & 414 & 587 \\
\hline Equivalent damping $\xi_{e q}$ & 13.62 & 13.64 & 13.49 \\
\hline Effective period $T(\mathrm{~s})$ & 1.70 & 2.65 & 3.30 \\
\hline Base shear $(\mathrm{kN})$ & 650 & 992 & 1,299 \\
\hline
\end{tabular}
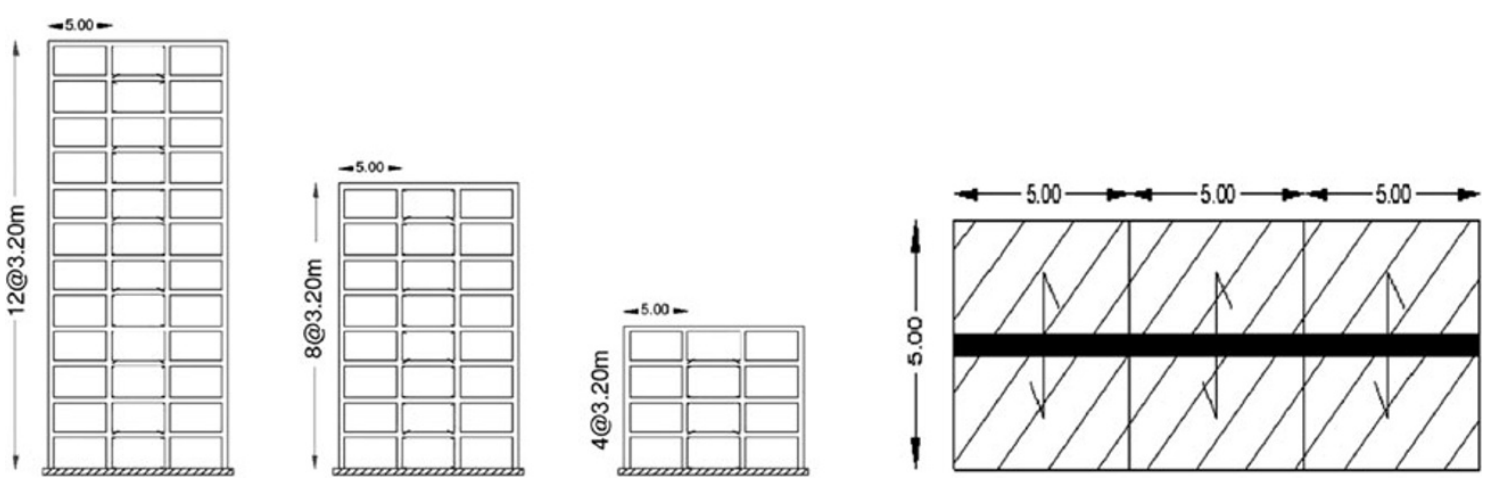

Fig. 6 Plan and elevation of the RC frame models.

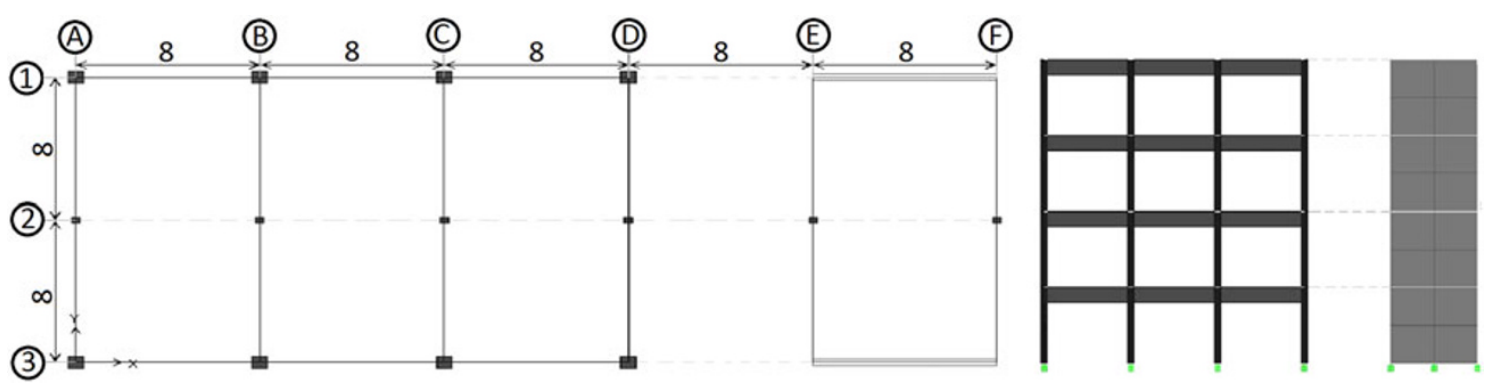

Fig. 7 Plan and elevation of the RC wall-frame models. 

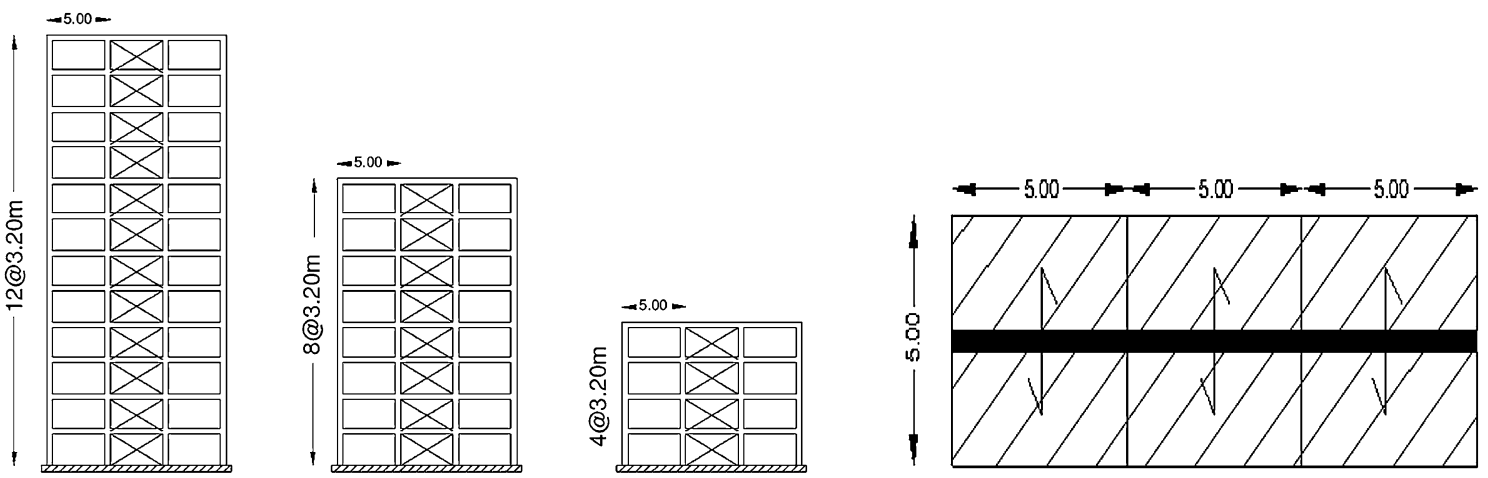

Fig. 8 Plan and elevation of the steel braced RC frame models.

Table 5 Final design results of RC steel braced frame models.

\begin{tabular}{c|c|c|c}
\hline & 4 storey & 8 storey & 12 storey \\
\hline \hline Brace section & 2 UNP120 & 2 UNP160 & 2 UNP200 \\
\hline Beam depth $\times$ width $(\mathrm{mm})$ & $400 \times 300$ & $450 \times 300$ & $500 \times 400$ \\
\hline Int. column depth $\times$ width $(\mathrm{mm})$ & $400 \times 400$ & $500 \times 500$ & $550 \times 550$ \\
\hline Ext. column depth $\times$ width $(\mathrm{mm})$ & $400 \times 400$ & $450 \times 450$ & $500 \times 500$ \\
\hline Inter storey height $(\mathrm{mm})$ & 3,200 & 3,200 & 3,200 \\
\hline
\end{tabular}

Table 6 Final design results of RC wall-frame models.

\begin{tabular}{c|c|c|c}
\hline & 4 storey & 8 storey & 12 storey \\
\hline \hline Wall length $(\mathrm{mm})$ & 8,000 & 8,000 & 3,000 \\
\hline Wall thickness $(\mathrm{mm})$ & 200 & 300 & 350 \\
\hline Beam depth $\times$ width $(\mathrm{mm})$ & $650 \times 400$ & $750 \times 450$ & $750 \times 450$ \\
\hline Int. column depth $\times$ width $(\mathrm{mm})$ & $650 \times 650$ & $750 \times 650$ & $750 \times 650$ \\
\hline Ext. column depth $\times$ width $(\mathrm{mm})$ & $550 \times 550$ & $650 \times 650$ & $650 \times 650$ \\
\hline Inter storey height $(\mathrm{mm})$ & 3,200 & 3,200 & 3,200 \\
\hline
\end{tabular}

Table 7 Final design results of RC frame models.

\begin{tabular}{c|c|c|c}
\hline & 4 storey & 8 storey & 12 storey \\
\hline \hline Beam depth $\times$ width $(\mathrm{mm})$ & $500 \times 450$ & $500 \times 450$ & $550 \times 500$ \\
\hline Int. column depth $\times$ width $(\mathrm{mm})$ & $580 \times 580$ & $600 \times 600$ & $625 \times 625$ \\
\hline Ext. column depth $\times$ width $(\mathrm{mm})$ & $580 \times 580$ & $600 \times 600$ & $625 \times 625$ \\
\hline Inter storey height $(\mathrm{mm})$ & 3,200 & 3,200 & 3,200 \\
\hline
\end{tabular}




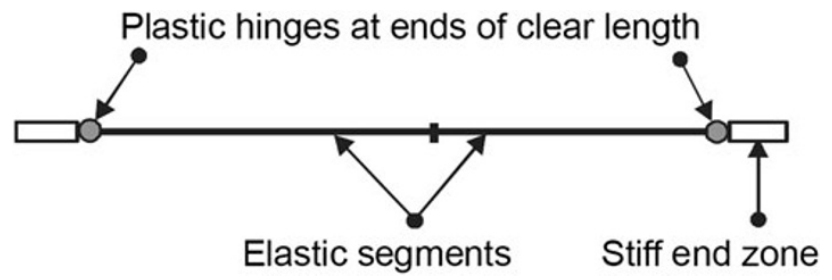

Fig. 9 Schematic view of FEMA beam element (PERFORM3D 2006).

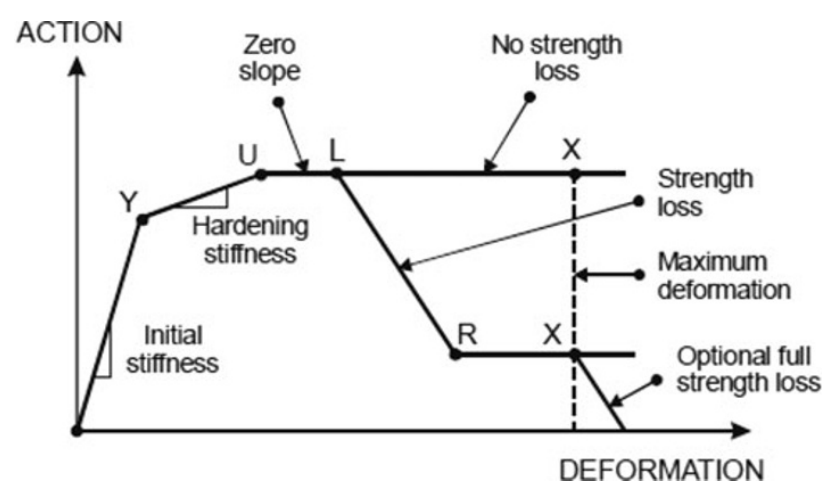

Fig. 10 PERFORM action-deformation relationship (PERFORM-3D 2006).

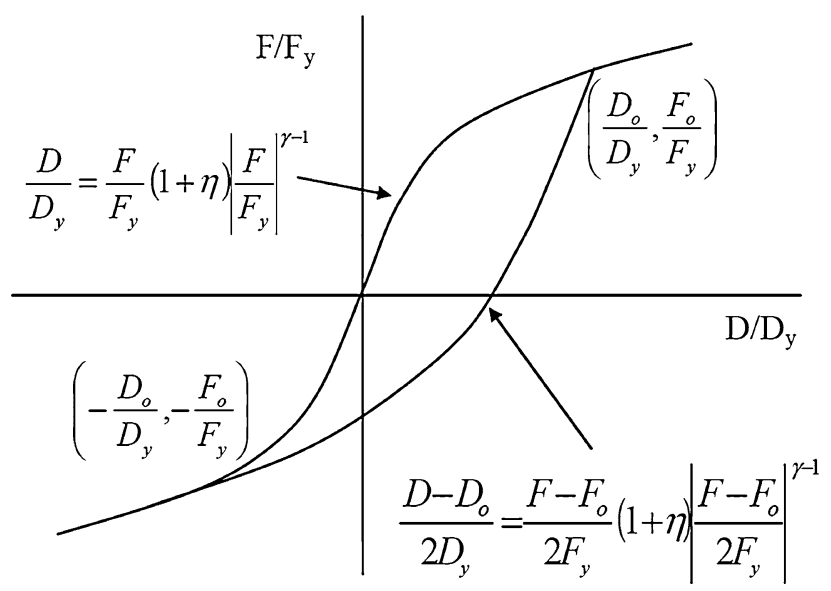

Fig. 11 Ramberg-Osgood curve (from Blandon 2004).

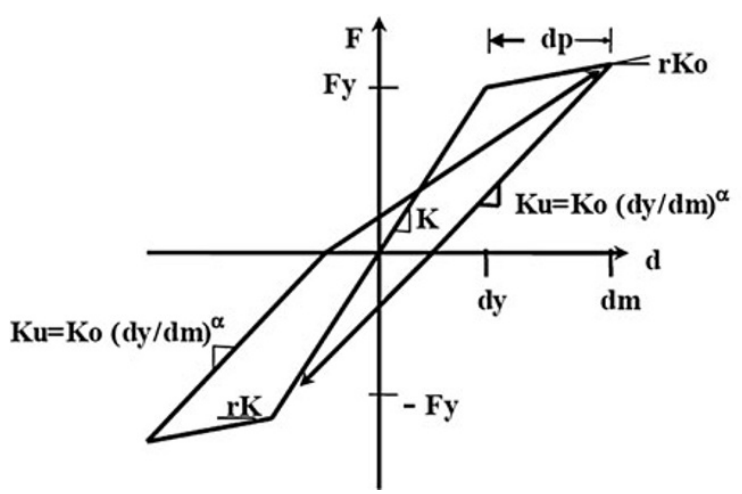

Figure 20 represents the inter-story drift profiles of the RC frame models under the selected pulse-type records. In these figures, the design inter-story drift profile is also displayed. Referring to these diagrams, the method performs quite satisfactorily. Maximum inter-story drifts in all RC frame models fall under the specified design profile. The overall profile shapes are similar to those expected for rigid frames. The shape of the profiles for the tall RC frame model (12 story frame) are very similar to natural higher mode shapes of these structures derived from Eigen-value analysis of frames, implying that higher mode effects are important for tall frames.

Figure 21 indicates inter-story drift profile of the RC wall-frame models. Displacement responses of the models are in close agreement with each other, and inter-story drifts of the all the models subjected to the records are below $2.5 \%$. All the lateral displacement responses exhibited some decrease in increasing displacement profile in upper stories which can be attributed to the fact that frames have dominant response in upper stories in comparison with structural walls.

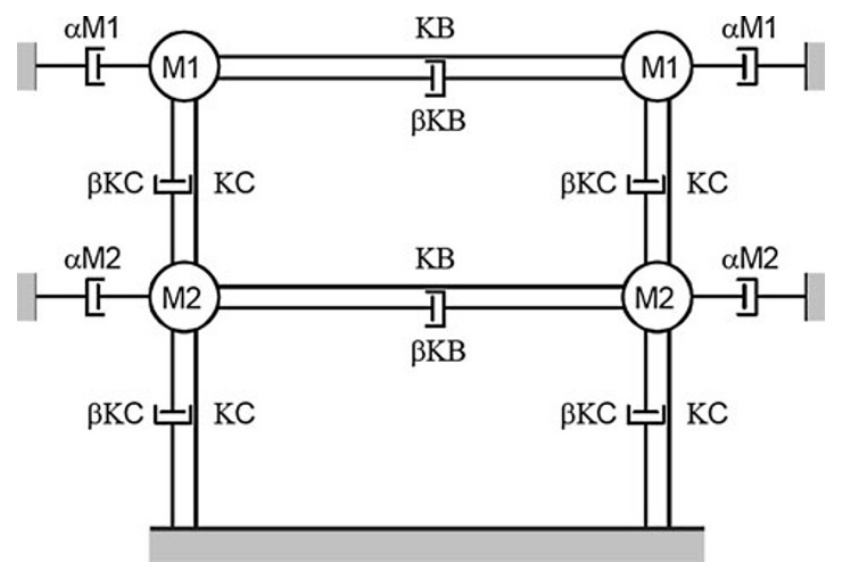

Fig. 13 Physical Meaning of $\alpha M+\beta K$ Dmping (PERFORM3D 2006).

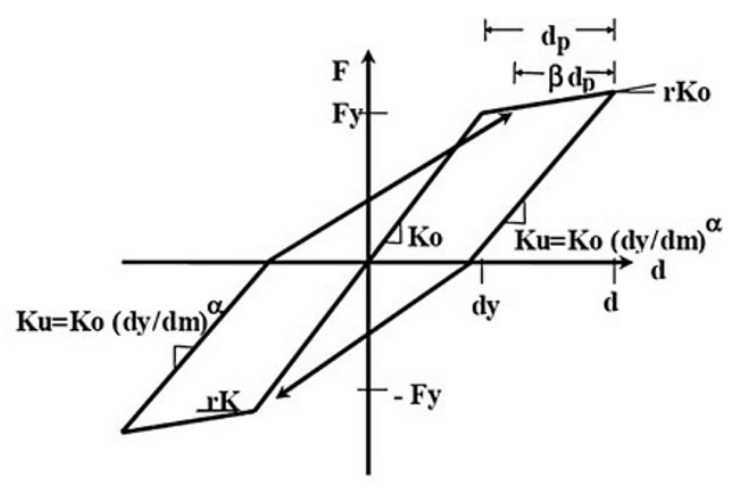

Fig. 12 Takeda model (from Blandon 2004). 
Table 8 Characteristics of the selected records.

\begin{tabular}{|c|c|c|c|c|c|}
\hline Peak acceleration (g) & $\begin{array}{l}\text { Minimum distance } \\
\text { from faulting }(\mathrm{km})\end{array}$ & Soil type (USGS) & Magnitude (Ms) & Years & Title \\
\hline 0.267 & 2.6 & $\mathrm{C}$ & 7.8 & 1999 & Kocali \\
\hline 0.09 & 2 & B & 7.3 & 1999 & Duzge \\
\hline 0.4966 & 4.38 & $\mathrm{C}$ & 6.69 & 1992 & Erzincan \\
\hline 0.519 & 4 & $\mathrm{C}$ & 7.62 & 1979 & Imperial valley \\
\hline 0.6357 & 8.34 & $\mathrm{C}$ & 6.9 & 1995 & Kobe \\
\hline 1.22 & 2.2 & $\mathrm{~B}$ & 6.6 & 1971 & Sanfernando \\
\hline 0.852 & - & C & - & 1970 & Tabas \\
\hline
\end{tabular}

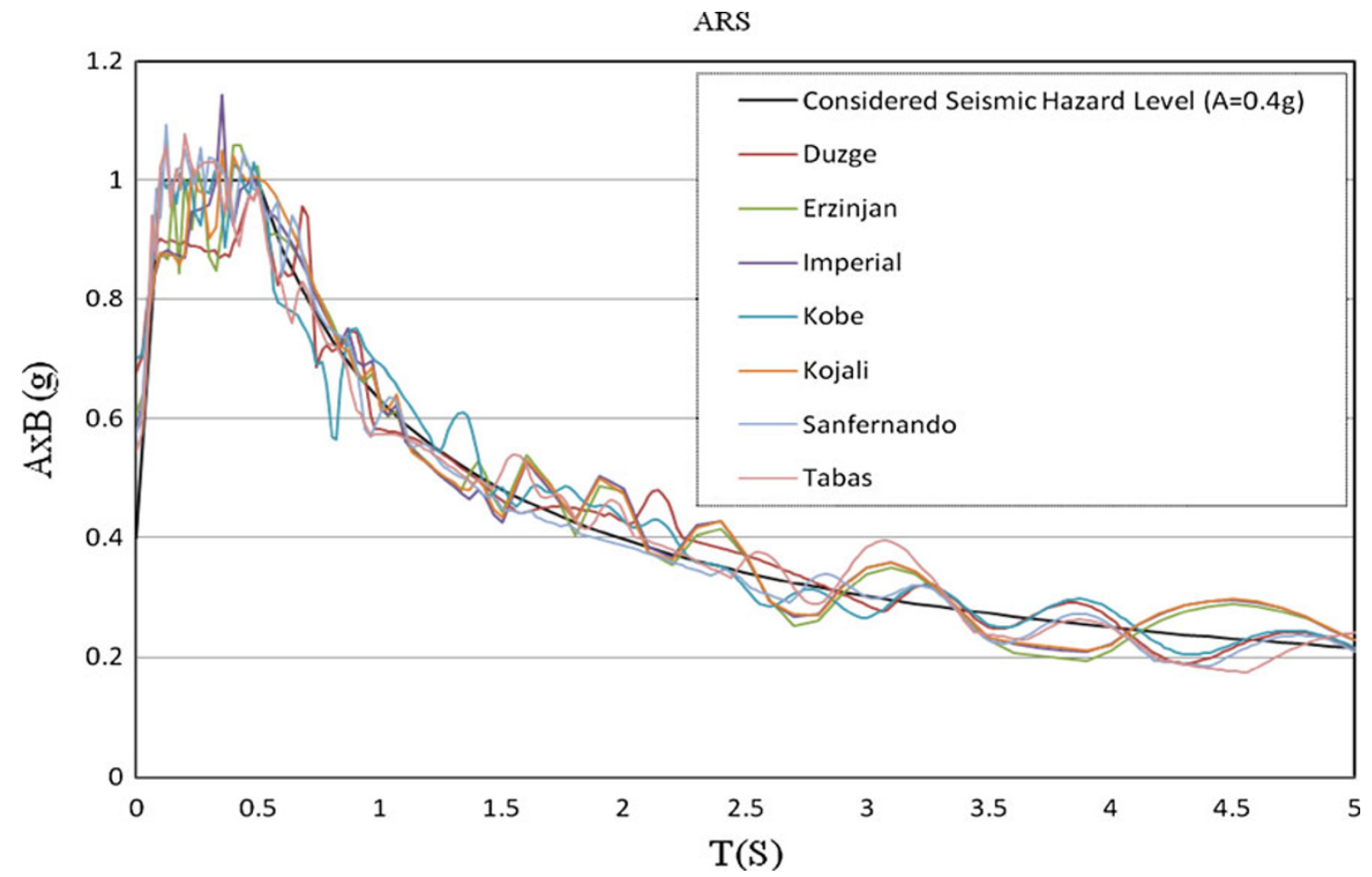

Fig. 14 Acceleration response spectrum of the accelerograms.

Figure 22 indicates inter-story drift profile of the steel braced RC frame models. The inter-story drifts of the 4 and 8-story models subjected to the records are below $2.5 \%$, but inter-story drift of the 12-story model subjected to the records exceeded the design inter-story drift in Stories 1-4, which can be attributed to the bracing buckling in lower stories. The inter-story drifts of the 4 and 8-story models subjected to the records are below $2.5 \%$, except for Imperial Valley Record in both models and Erzincan and Sanfernando Record in the 8-story model. However, inter-story drift of the 12-story model subjected to the records exceeded the design inter-story drift in Stories 1-4 demonstrating the fact that this design method was not successful for the 12-story model. 

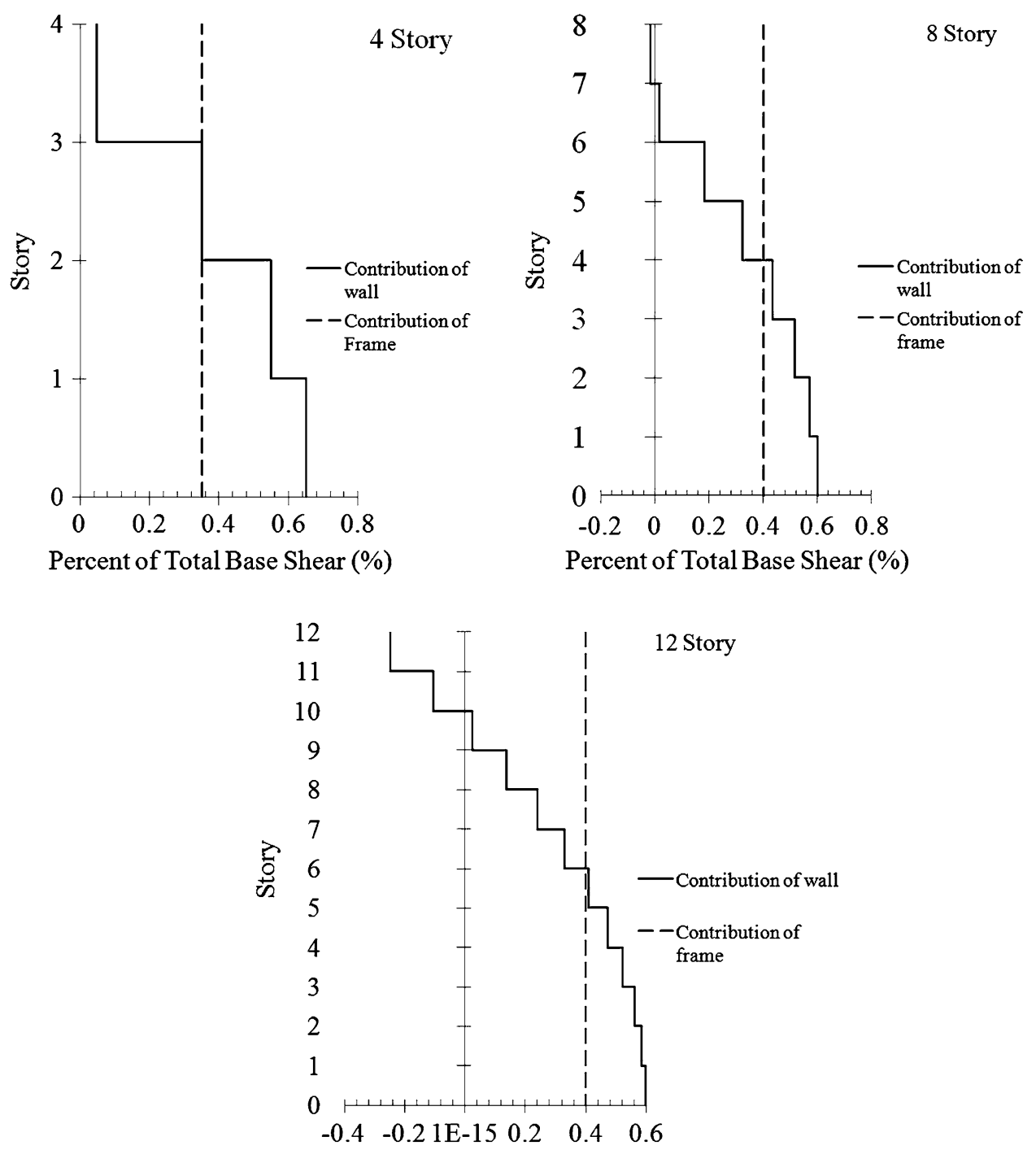

Percent of Total Base Shear (\%)

Fig. 15 Profile of the story shear assignment to the frame and wall.

\section{Concluding Remarks}

The present study focuses on seismic behavior of nearfault RC structures design with a new performance-based design tool called the DDBD.

For this purpose, seismic response of $\mathrm{RC}$ frame systems in addition to dual RC wall-frame and steel braced RC frame systems designed using DDBD are investigated.

Performance verification studies show that the method can be regarded as an appropriate alternative to current forcebased seismic design of structures. The method, performed quite satisfactorily in term of maximum inter-story drift, even for tall models. Some deviations, especially in tall models, from design values are mainly due to the complex and highly varying nature of frequency content of near-fault records. Another important finding of the study is that, the DDBD methodology is able to design structures with quite controlled residual behavior, an interesting subject which needs further studies.

\section{Open Access}

This article is distributed under the terms of the Creative Commons Attribution License which permits any use, distribution, and reproduction in any medium, provided the original author(s) and the source are credited. 

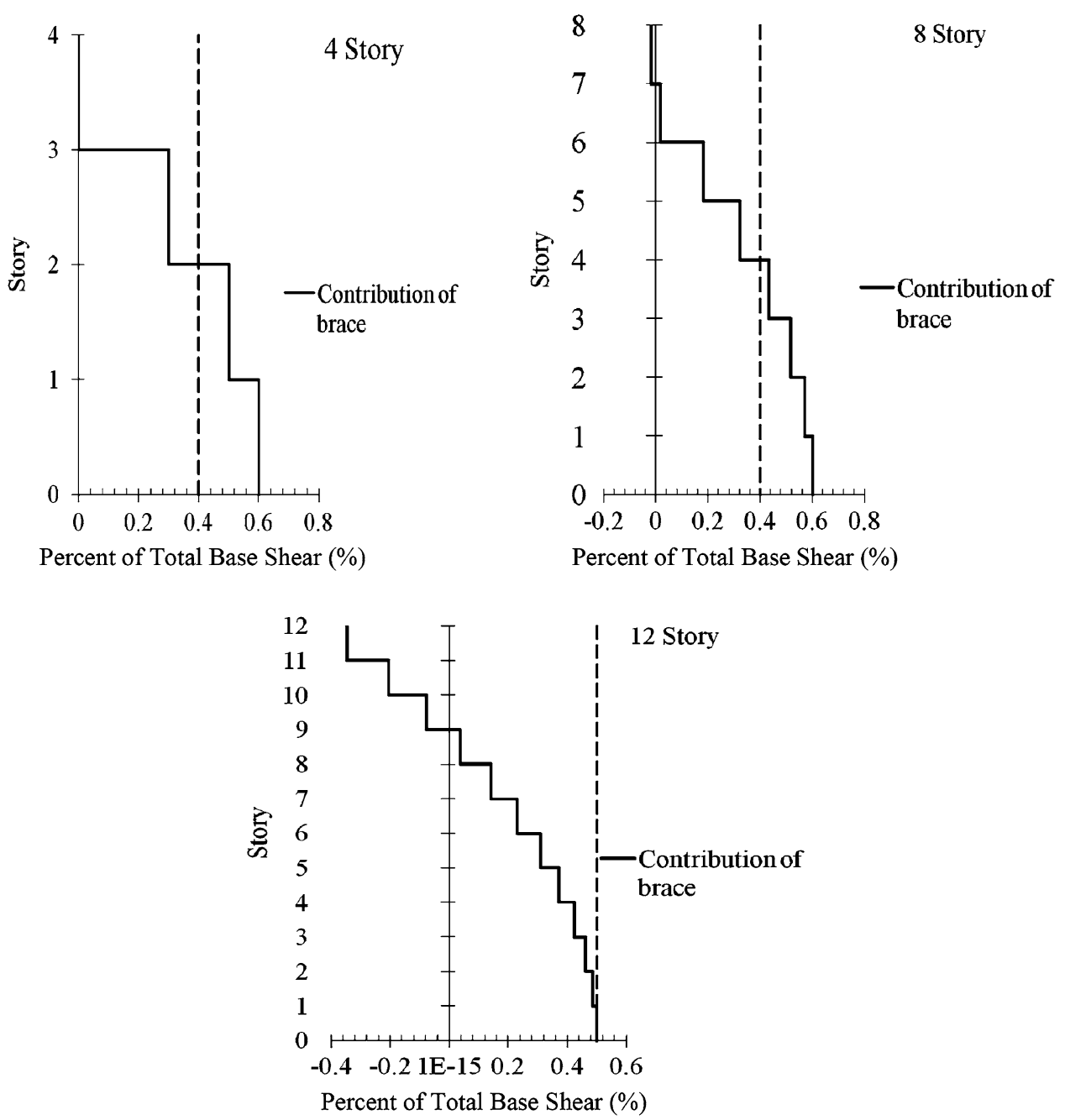

Fig. 16 Profile of the story shear assignment to the frame and bracing.
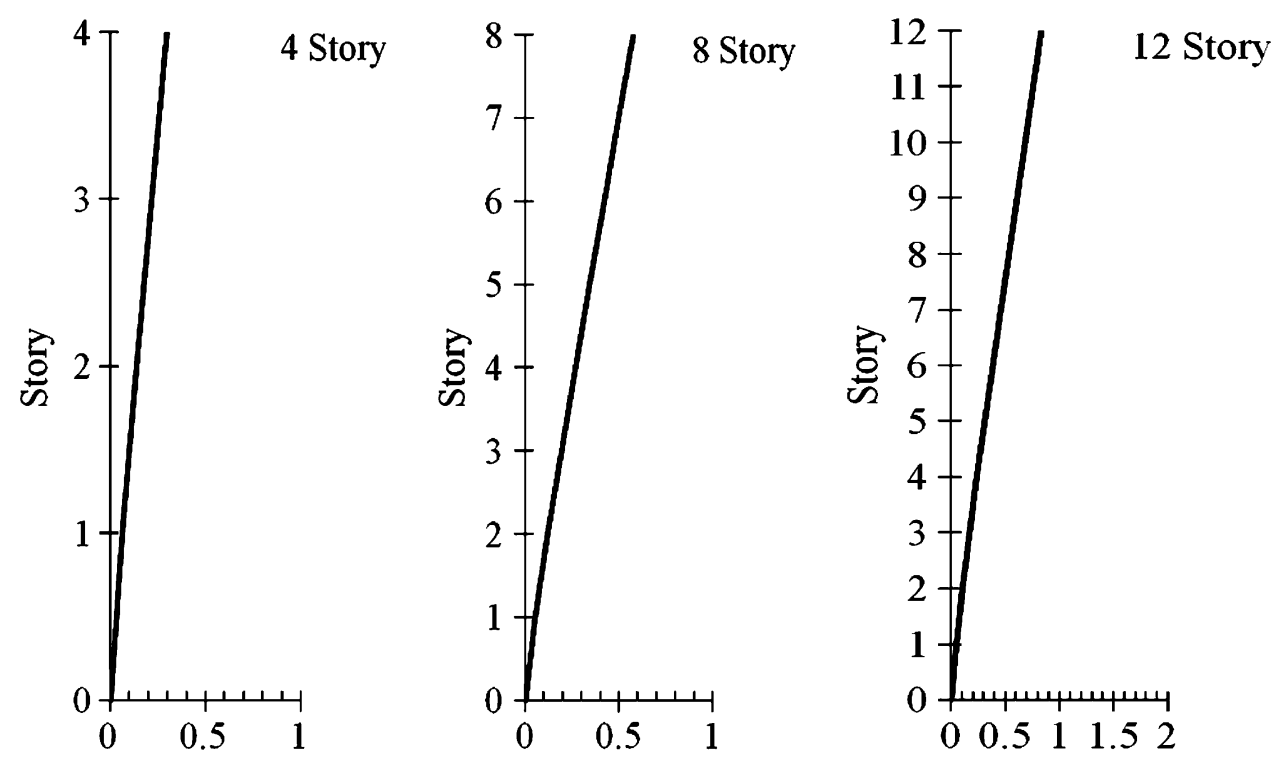

Fig. 17 Displacement profile of RC frame models. 


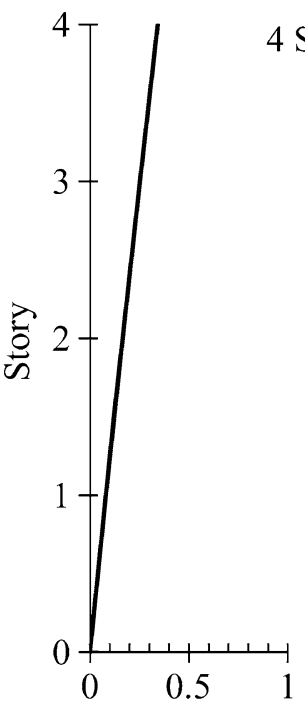

Displacement $(\mathrm{m})$

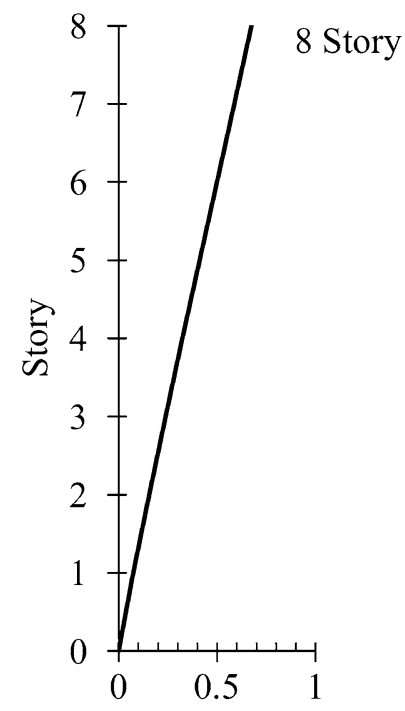

Displacement (m)

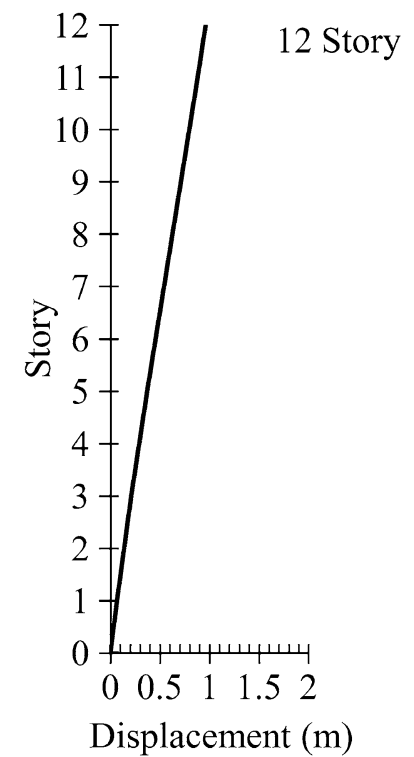

Displacement (m)

Fig. 18 Displacement profile of RC wall-frame model.

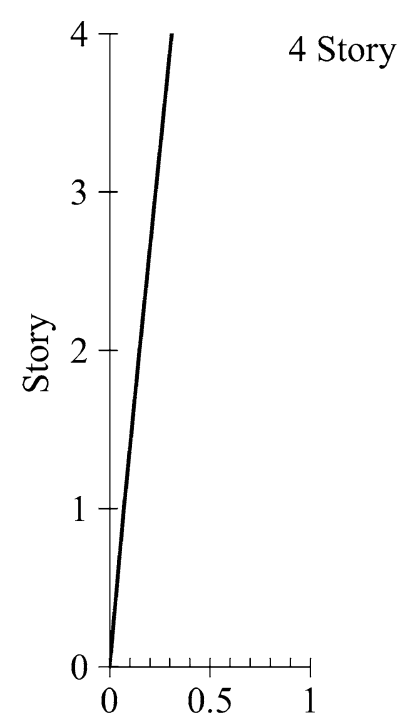

Displacement (m)
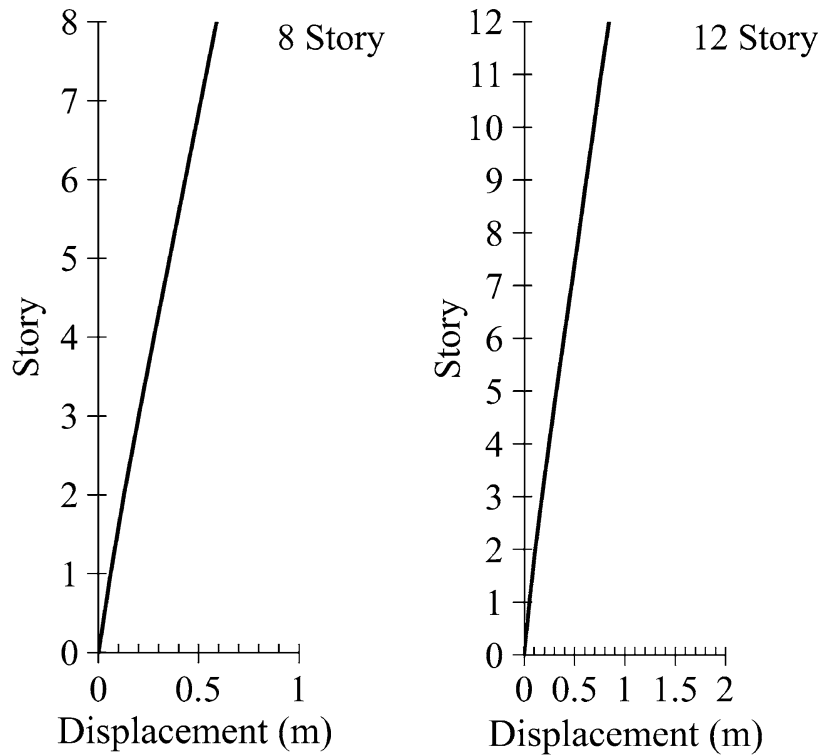

Fig. 19 Displacement profile of steel braced RC frame models. 


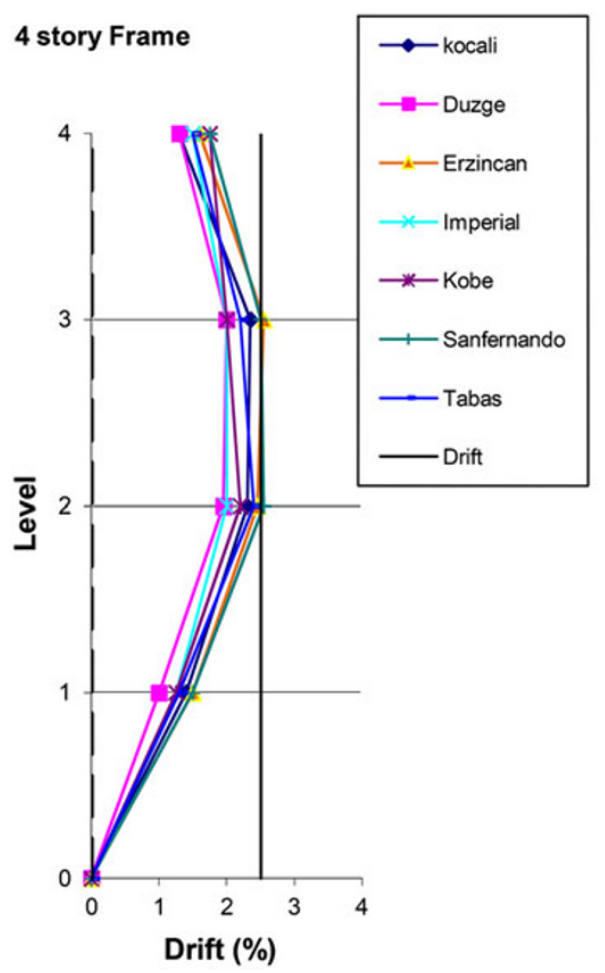

\section{8 story Frame}

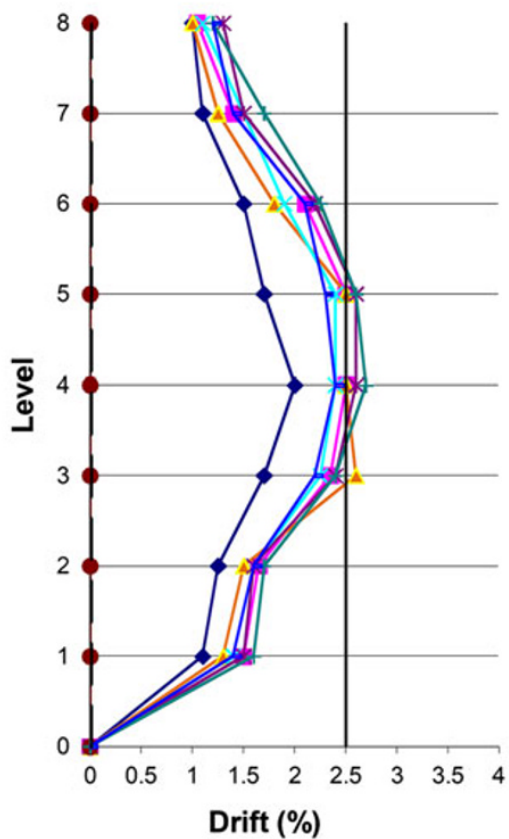

12 story Frame

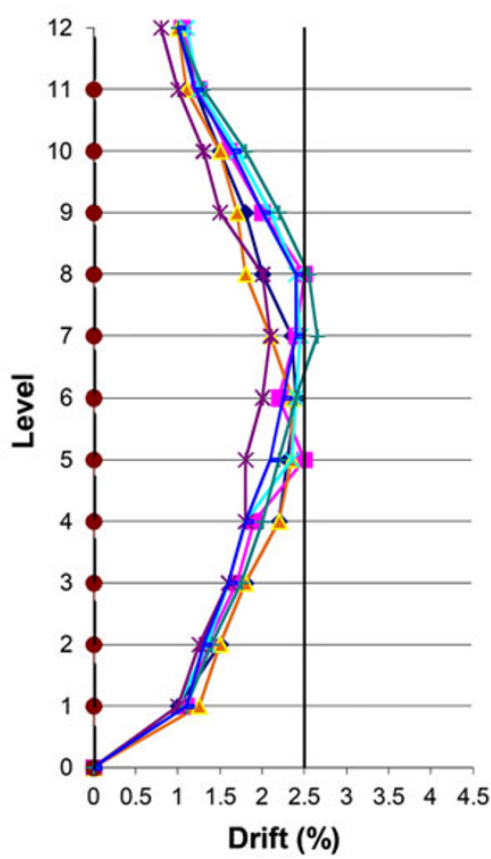

Fig. 20 Inter-story drift profile of RC frame models.

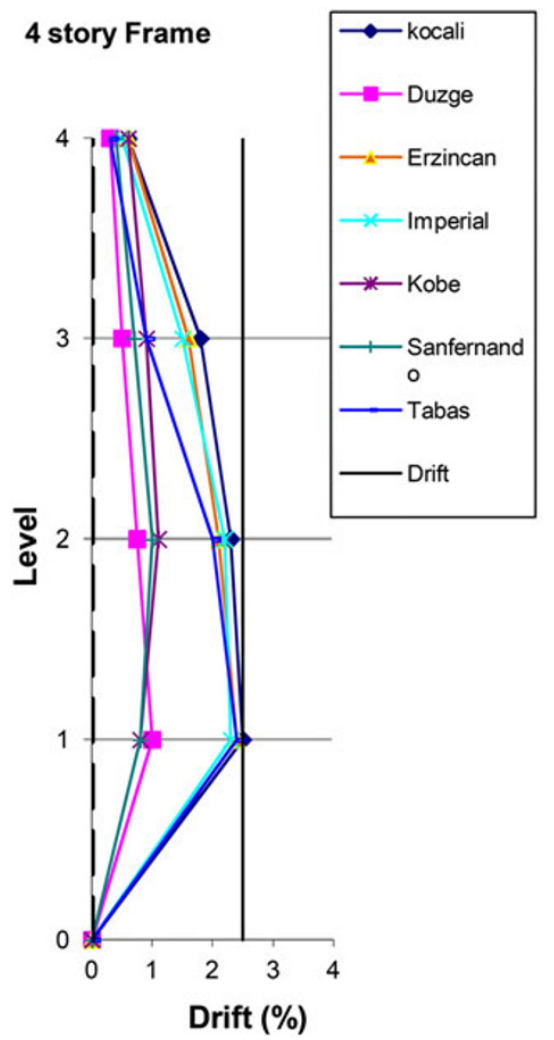

8 story Frame

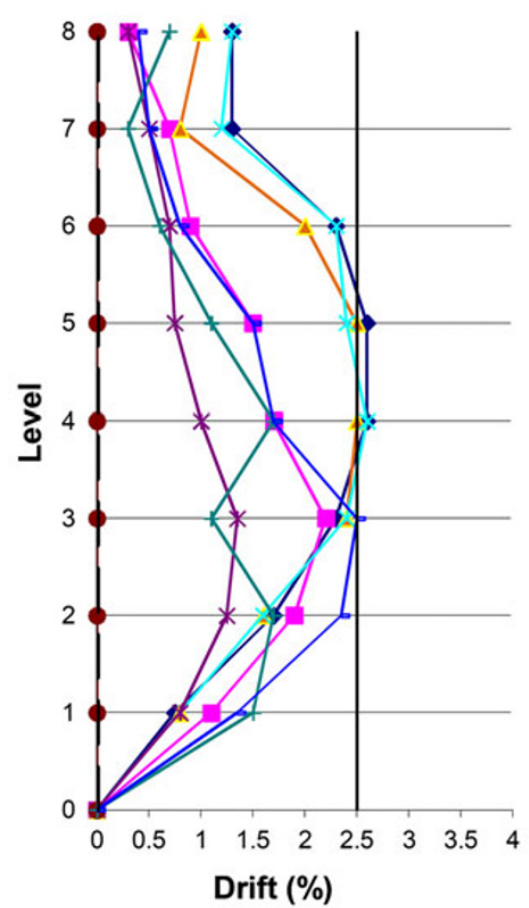

12 story Frame

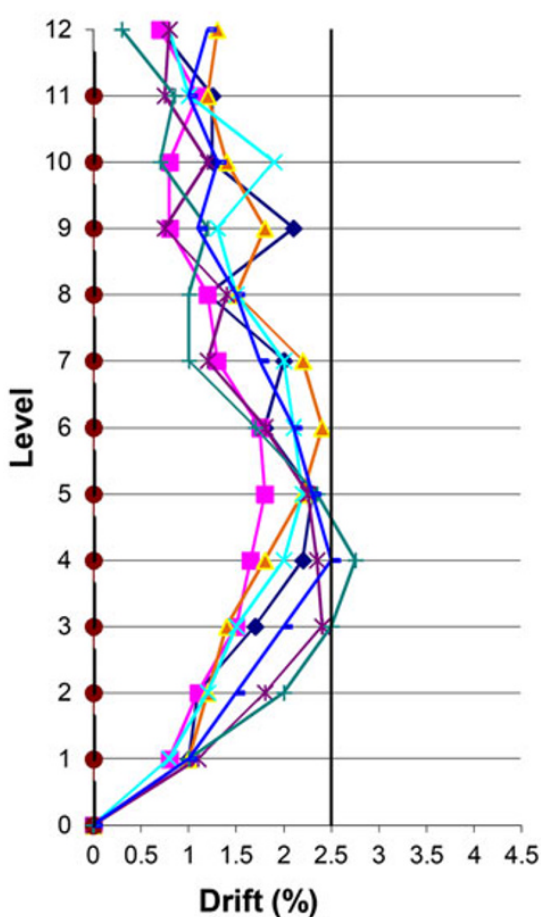

Fig. 21 Inter-story drift profile of RC wall-frame model. 


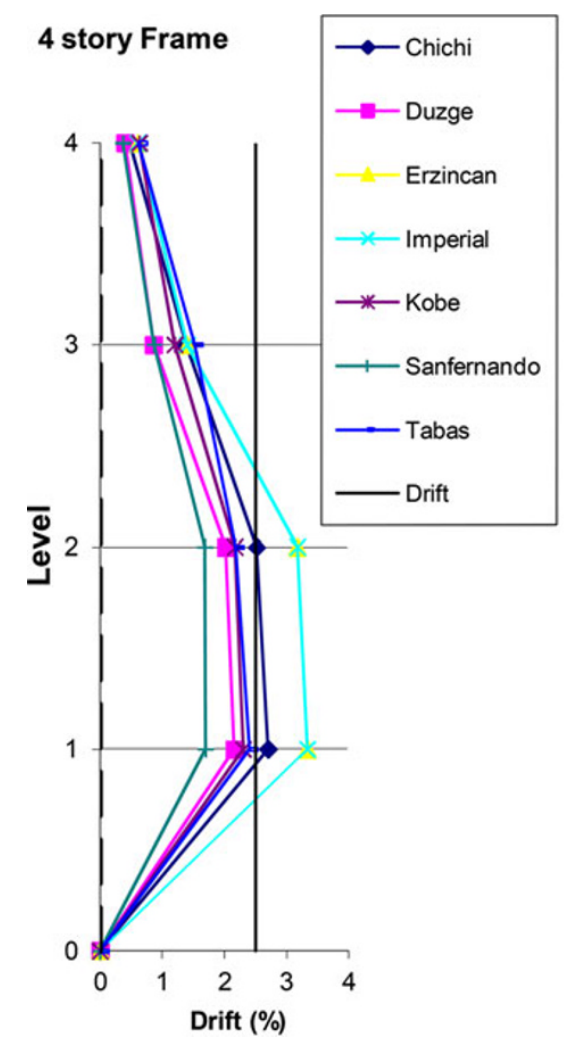

\section{8 story Frame}

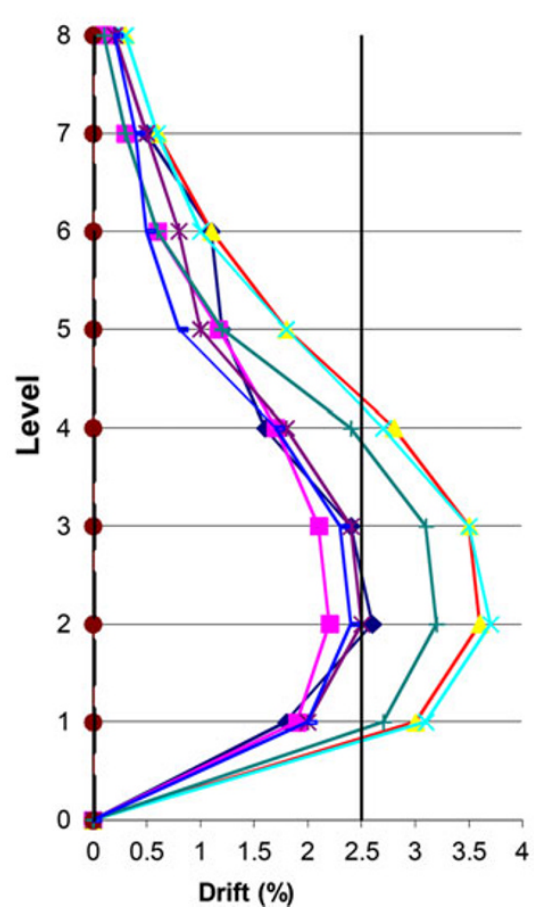

12 story Frame

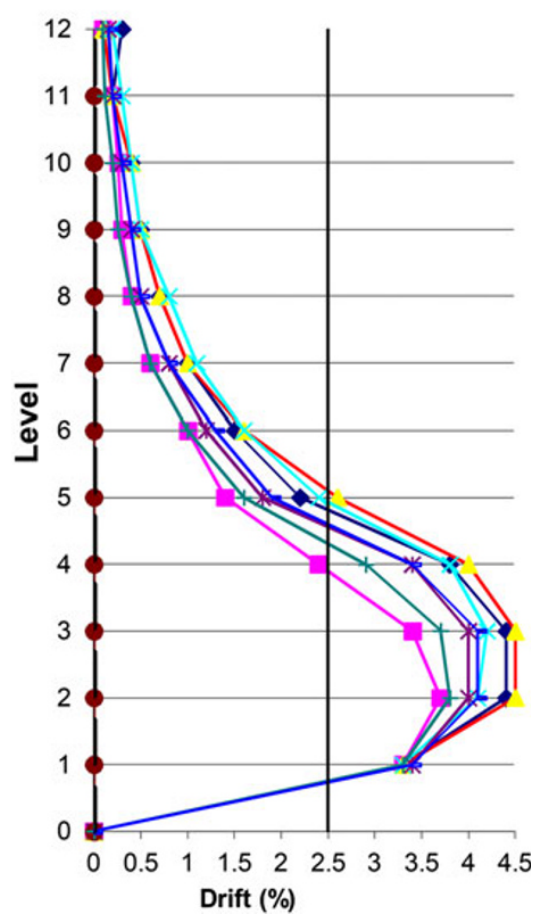

Fig. 22 Inter-story drift profile of steel braced RC frame models.

\section{References}

Badoux, M., \& Jirsa, J. O. (1990). Steel bracing of RC frames for seismic retrofitting. Journal of Structural Engineering, ASCE, 116(1), 55-74.

Belleri, A. (2009). Displacement based design for precast concrete structures. PhD thesis, University of Toronto.

Blandon, C. A. (2004). Equivalent Viscous Damping for DDBD. MSc Thesis, ROSE School, Pavia, Italy.

Calvi, G. M., \& Pavese, A. (1995). Displacement-based design of building structures. In A. S. Elnashai (Ed.), European seismic design practice: Research and application, proceedings of the fifth SECED conference, Chester, United Kingdom, October 26-27 1995 (pp. 127-132). Rotterdam, Netherlands: A.A. Balkema.

Calvi, G. M., \& Kingsley, G. R. (1995). Displacement-based seismic design of multi-degree-of-freedom bridge structures. Earthquake Engineering and Structural Dynamics, 24, 1247-1266.

CEN. (1998). Eurocode 8: Design provisions for earthquake resistance of structures, prEN-1998-1:200X, Revised Final PT Draft (preStage 49). Brussels, Belgium: Committee European de Normalization.

Chopra, A. K., \& Goel, R. K. (2001). Direct displacement-based design: Use of inelastic vs. elastic design spectra. Earthquake Spectra, EERI, 17(1), 47-64.

Fajfar, P. (2000). A nonlinear analysis method for performancebased seismic design. Earthquake Spectra, 16(3), 573-592.

Fardis, M. N., Panagiotakos, T. B., \& Telemachos, B. (1997). Displacement-based design of RC buildings: Proposed approach and application. In P. Fajfar \& H. Krawinkler (Eds.), Proceedings of the seismic design methodologies for the next generation of codes. Bled, Slovenia, June 24-27 1997 (pp. 195-206). Rotterdam, Netherlands: A.A. Balkema.

FEMA 356. (2002). Prestandard and commentary for the seismic rehabilitation of buildings. Washington, D.C.: Federal Emergency Management Agency.

Freeman, S. A. (1998). The capacity spectrum method as a tool for seismic design. In Proceedings of the 11th European Conference on Earthquake Engineering, Sept 6-11, Paris, France.

Garcia, R., Sullivan, T. J., \& Della Corte, G. (2010). Development of a displacement-based design for steel frame-RC wall buildings. Journal of Earthquake Engineering, 14(2), 252-277.

Ghaffarzadeh, H., \& Maheri, M. R. (2006a). Cyclic tests on the internally braced RC frames. Journal of Seismology and Earthquake Engineering, 8(3), 177-186.

Ghaffarzadeh, H., \& Maheri, M. R. (2006b). Mechanical compression release device in steel bracing system for retrofitting RC frames. Journal of Earthquake Engineering and Engineering Vibration, 5(1), 151-158. doi:10.1007/s11803006-0626-x.

Ghorbani-Asl, A. (2007). Performance-based seismic design of building structure. Doctor of Philosophy in Civil Engineering. Ottawa-Carleton Institute for Civil Engineering, Carleton University, Ottawa, Canada.

Gulkan, P., \& Sozen, M. (1974). Inelastic response of reinforced concrete structures to earthquake motions. ACI Journal, 71(12), 604-610. 
Higashi, Y., Endo, T., \& Shimizu, Y. (1981). Experimental studies on retrofitting of reinforced concrete structural members. In Proceedings of the Second Seminar on Repair and Retrofit of Structures (pp. 126-155). Ann Arbor, MI: National Science Foundation.

Iranian Code of Practice for Seismic Resistant Design of Buildings, Standard No. 2800, 3rd edition. (2005). Building and Housing Research Center, BHRC-PN S 253.

Jacobsen, L. S. (1930). Steady forced vibration as influenced by damping. Transactions of ASME, 52, 169-181.

Kowalsky, M. J., Priestley, M. J. N., \& MacRae, G. A. (1995). Displacement-based design of RC bridge columns in seismic regions. Journal of Earthquake Engineering and Structural Dynamics, 24(12), 1623-1643.

Maheri, M. R., \& Ghaffarzadeh, H. (2008). Connection overstrength in steel-braced RC frames. Journal of Engineering Structures, 30, 1938-1948.

Maheri, M. R., \& Sahebi, A. (1997). Use of steel bracing in reinforced concrete frames. Engineering Structures, 19(12), 1018-1024.

Malekpour, S., Ghaffarzadeh, H., \& Dashti, F. (2012). Direct displacement-based design of steel-braced reinforced concrete frames. Journal of the Structural Design of Tall and Special Buildings. doi:10.1002/tal.1028.

Moehle, J. P. (1992). Displacement-based design of RC structures subjected to earthquakes. Earthquake Spectra, EERI, $8(3), 403-428$.

Pennucci, D., Calvi, G. M., \& Sullivan, T. J. (2009). Displacement-based design of precast walls with additional dampers. Journal of Earthquake Engineering, 13(1), 40-65.

PERFORM-3D User Guide. (2006). Nonlinear analysis and performance assessment for 3D structures, VERSION 4, August 2006. Berkeley, CA: Computers and Structures, Inc.

Pettinga, J. D., \& Priestley, M. J. N. (2005). Dynamic behaviour of reinforced concrete frames design with direct displacement-based design. Journal of Earthquake Engineering, 9(2), 309-330.
Priestley, M. J. N. (2003). Myths and fallacies in earthquake engineering, revisited, The Mallet Milne Lecture. Pavia, Italy: IUSS Press.

Priestley, M. J. N., \& Grant, D. N. (2005). Viscous damping for analysis and design. Journal of Earthquake Engineering, 9 (Special Issue 2), 229-255.

Priestley, M. J. N., \& Kowalsky, M. J. (2000). Direct displacement-based design of concrete buildings. Bulletin of the New Zealand National Society for Earthquake Engineering, 33(4), 421-444.

Shibata, A., \& Sozen, M. A. (1976). Substitute-structure method for seismic design in R/C. Journal of the Structural Division, 102(1), 1-18.

Sullivan, T. J., Priestley, M. J. N., \& Calvi, G. M. (2005). Development of an innovative seismic design procedure for frame-wall structures. Journal of Earthquake Engineering, 9 (Special Issue 2), 279-307.

Sullivan, T. J., Priestley, M. J. N., \& Calvi, G. M. (2006). Direct displacement design of frame-wall structures. Journal of Earthquake Engineering, 10(Special Issue 1), 91-124.

Sullivan, T. J., Priestley, M. J. N., \& Calvi, G. M. (2004). Displacement shapes of framewall structures for direct displacement based design. In Proceedings of Japan-Europe 5th Workshop on Implications of Recent Earthquakes on Seismic Risk, Bristol, UK.

Sullivan, T. J., Priestley, M. J. N., \& Calvi, G. M. (2009). Introduction to a model code for displacement-based seismic design. In Proceedings, ACES Workshop on Performance-Based Earthquake Engineering. Corfu, Greece.

Tasnimi, A. A., \& Masoomi, A. (1999). Evaluation of response of reinforced concrete frames strengthened with steel bracing. In Proceedings of the Third International Conference on Seismology and Earthquake Engineering, Iran, (in Farsi).

Youssef, M., Ghaffarzadeh, H., \& Nehdi, M. (2007). Seismic performance of RC frames with concentric internal steel bracing. Journal of Engineering Structures, 29, $1561-1568$. 